\title{
A Self-Consistent Scheme for Understanding Particle Impact and Adhesion in the Aerosol Deposition Process
}

\author{
Robert Saunders $^{1} \cdot$ Scooter D. Johnson ${ }^{1} \cdot$ Douglas Schwer $^{2} \cdot$ Eric A. Patterson ${ }^{1}$ • \\ Heonjune Ryou ${ }^{1}$ Edward P. Gorzkowski ${ }^{1}$
}

Submitted: 27 August 2020/in revised form: 9 December 2020/Accepted: 12 January 2021/Published online: 5 February 2021

(C) This is a U.S. government work and not under copyright protection in the U.S.; foreign copyright protection may apply 2021

\begin{abstract}
Aerosol deposition (AD) is a thick-film deposition process that can produce films tens to hundreds of micrometers thick with densities greater than $95 \%$ of the bulk at room temperature. However, the precise mechanisms of bonding and densification are still under debate. To better understand and predict deposition, a self-consistent approach is employed that combines computational fluid dynamics (CFD), finite element (FE) modeling, and experimental observation of particle impact to improve the understanding of particle flight, impact, and adhesion in the $\mathrm{AD}$ process. First, deposition is performed with a trial material to form a film. The process parameters are fed into a CFD model that refines the particle flow and impact velocity for a range of sizes. These values are in turn used to inform the FE parameters to model the fracture and adhesion of the particle on the substrate. The results of FE modeling are compared to SEM images of fractured particles to complete a self-consistent numerical and experimental understanding of the $\mathrm{AD}$ process. Additional FE and CFD simulations are used to study how process
\end{abstract}

This article is part of a special topical focus in the Journal of Thermal Spray Technology on Aerosol Deposition and Kinetic Spray Processes. This issue was organized by Dr. Kentaro Shinoda, National Institute of Advanced Industrial Science and Technology (AIST); Dr. Frank Gaertner, Helmut-Schmidt University; Prof. Changhee Lee, Hanyang University; Prof. Ali Dolatabadi, Concordia University; and Dr. Scooter Johnson, Naval Research Laboratory.

Robert Saunders

robert.saunders@nrl.navy.mil

1 Multifunctional Materials Branch, Code 6350, US Naval Research Laboratory, Washington, DC 20375, USA

2 Laboratory for Propulsion, Energetic, and Dynamic Systems, Code 6041, US Naval Research Laboratory, Washington, DC 20375, USA parameters, materials, and particle parameters affect the deposition process and how the developed tools can be used to optimize deposition efficiency.

Keywords Aerosol deposition - experiments · gas flow · particle fracture $\cdot$ particle tracking $\cdot$ simulation

\section{Introduction}

Aerosol deposition (AD) is a thick-film room-temperature deposition process that has been utilized to produce dense polycrystalline ceramic films. The process was developed in the late 1990s in Japan by Akedo et al. (Ref 1) and is now used by researchers around the world. Deposition is accomplished by forming an aerosol of dry particles of submicron size (on average $0.5 \mu \mathrm{m}$ in size), typically, by use of powder fluidization or agitation. The aerosolized powder is then forced from the aerosol chamber (AC) held at about 330-660 mbar into the deposition chamber (DC), held at 1.33-20 mbar, where the pressure differential accelerates the particles toward the substrate. Upon impact on the substrate, the particle deforms plastically eventually leading to fracture and then bonding with the substrate (Ref 2). Continued impact of subsequent particles further fractures the particle grains to $10-200 \mathrm{~nm}$ in size while continuing to promote densification of the film. The main features of $\mathrm{AD}$ film growth are that it can produce micrometers-thick films that are dense (90-95\% of theoretical density) from a solid precursor at room temperature (Ref 3, 4). Much work has been published that shows promise for a wide range of applications, including integration of high-melting temperature materials into temperature-sensitive structures (Ref 5). Reviews of current $\mathrm{AD}$ technology can be found in the literature $(\operatorname{Ref} 6,7)$. 
There have been some efforts on simulating the gas and particle flow from nozzles in AD and cold spray. Gas and particle velocities for cold spray (CS) were estimated using an isentropic gas flow model that provides a framework for analytical calculations of gas velocities (Ref 8,9$)$. More recent work using numerical simulation of $\mathrm{Al}_{2} \mathrm{O}_{3}$ particles between 0.5 and $15 \mu \mathrm{m}$ in size suggests that particle velocity can be tuned both by the particle size and pressure in the deposition chamber (Ref 10,11). Simulations of gas flow using different nozzle sizes, chamber pressures, and substrate standoff distances suggest the importance of tuning these parameters to optimize the gas flow (Ref 12). It was found that the average impact velocity of $0.5 \mu \mathrm{m}$ particles was between $335 \mathrm{~m} / \mathrm{s}$ and $346 \mathrm{~m} / \mathrm{s}$ for standoff distances between 1 and $7 \mathrm{~mm}$, respectively. Previous work at the US Naval Research Laboratory (NRL) (Ref 13) was consistent with these results, showing impact velocities up to $300 \mathrm{~m} / \mathrm{s}$ for $1 \mu \mathrm{m}$ alumina particles with standoff distances of 7.5 and $10 \mathrm{~mm}$. This work examined particle and tracer (massless particles) trajectories as they exit the nozzle and impact the substrate (or are carried off by the gas phase).

Finite element (FE) structural simulations of the $\mathrm{AD}$ process are less common than their CFD counterparts but can provide critical information about particle adhesion to the substrate. Fundamentally, the simulations of the AD process and the CS process are nearly identical; thus, knowledge from CS can be used in aiding understanding of AD. In CS FE simulations, a multitude of techniques such as Lagrangian (Ref 14-16), Eulerian (Ref 17, 18), arbitrary Lagrangian-Eulerian (ALE) (Ref 19-21), smoothed particle hydrodynamics (SPH) (Ref 22, 23), and molecular dynamics (MD) (Ref 24) have all been used to simulate particle impact and adhesion (Ref 25, 26). These can almost be directly applied to the AD process simulation. However, some key differences in the methods and subsequent deformation mechanism between $\mathrm{CS}$ and $\mathrm{AD}$ must be considered. In CS, an elevated temperature is used to adhere the particle to a substrate, which leads to a large amount of plastic deformation with particle fracture, generally, being insignificant to the process. However, in the $\mathrm{AD}$ process, fracture is the driving mechanism and makes some CS simulation methods infeasible. Lagrangian or ALE simulations (Ref 27, 28) can be used to capture thermal and small strain behaviors of the initial particle impact but suffer from numerical instabilities when large amount of damage and fracture is included. Methods such as SPH (Ref 2, 29), material point method (MPM) (Ref 30), and MD (Ref 31,32) are able to capture the full physics of the AD particle fracturing but can suffer from long computational times for simulations of even a single particle with multiparticle simulations being almost completely infeasible. In previous works involving AD FE simulations, conclusions have been made about methods of particle adhesion but generally, these studies are limited to a single set of parameters or a fixed material system.

In order to further optimize and control the AD process, further study is needed to understand and optimize the particle flight and impact characteristics. There are several factors that can influence film formation, including nozzle and AC design, particle size, particle composition, substrate composition, and gas flow rate. For example, it has been established that the stability of the aerosol in the AC is critical to creating uniform and consistent films over the course of the deposition process (Ref 13, 33). There have also been studies on the role of nozzle design (Ref 12) and powder treatment (Ref 34) in the deposition.

In this work, we aim to add to the understanding of the $\mathrm{AD}$ process by comparing a computational approach to model particle flow and impact with experimental results of individual particle impacts. This is accomplished by first performing experiments with a fixed set of parameters, which are fed into the CFD and FE models. The CFD results are also fed into the FE model and then compared to the experiments to construct a self-consistent, validated framework. The validated computational portions of the framework are also used to explore the parameters space in an efficient manner, and these results can be used to inform future studies and optimize the deposition process for maximum efficiency.

\section{Deposition Experiments}

\section{Materials and Methods}

Deposition was performed using a custom-built AD system at NRL and described in the literature $(\operatorname{Ref} 3,35-37)$. The system utilizes a $5 \times 0.4 \mathrm{~mm}^{2}$ converging nozzle. For this work, we used a 30-g-capacity tee-shaped AC mounted on a vibration plate to fluidize the powder. The tee-shaped chamber was oriented so the gas flow could enter horizontally through two ports and the aerosol would flow vertically through the third port into the deposition chamber. The carrier gas was breathing quality compressed air flowing at $10.5 \mathrm{l} / \mathrm{min}$.

Scanning electron microscope (SEM) images were taken in backscatter mode at a chamber pressure of $30 \mathrm{~Pa}$ using a JEOL JSM-7001F (JEOL, Ltd.). The SEM has a variable chamber pressure capability that allows imaging of nonconductive samples at low vacuum (1-50 Pa). The loose starting powder and films were imaged by mounting the samples onto conductive carbon tape adhered to an aluminum SEM sample holder. For powder samples, excess powder was removed by gently blowing the surface with bottled $\mathrm{CO}_{2}$. For chemical analysis, energy-dispersive 
$\mathrm{x}$-ray spectroscopy (EDS) was performed using an EDAX Octane Super detector (AMETEK Inc.). The accelerating voltage was set to $10 \mathrm{kV}$ for imaging and EDS.

$\mathrm{X}$-ray diffraction (XRD) scans were performed for phase identification (Rigaku, SmartLab, Tokyo, Japan) on both the powders and the resulting films at a setting of $40 \mathrm{kV}$ and $200 \mathrm{~mA}$. Rietveld refinement, peak fitting, and crystallite size analysis were performed using a commercially available PDXL software package (Rigaku, SmartLab, Tokyo, Japan). ImageJ version 1.52a (National Institutes of Health, USA, http://imagej.nih.gov/ij) was used for image analysis (Ref 38).

\section{Powder and Film Deposition Assessment}

Commercially available $\mathrm{Al}_{2} \mathrm{O}_{3}$ powder (Inframat Corp., Manchester, CT, USA) was purchased with a nominal size range, as specified by the manufacturer, of 1-2 $\mu \mathrm{m}$. After sieving with a $125-\mu \mathrm{m}$-sized opening sieve and heattreating the powders at $300^{\circ} \mathrm{C}$, initial film depositions were

(a)

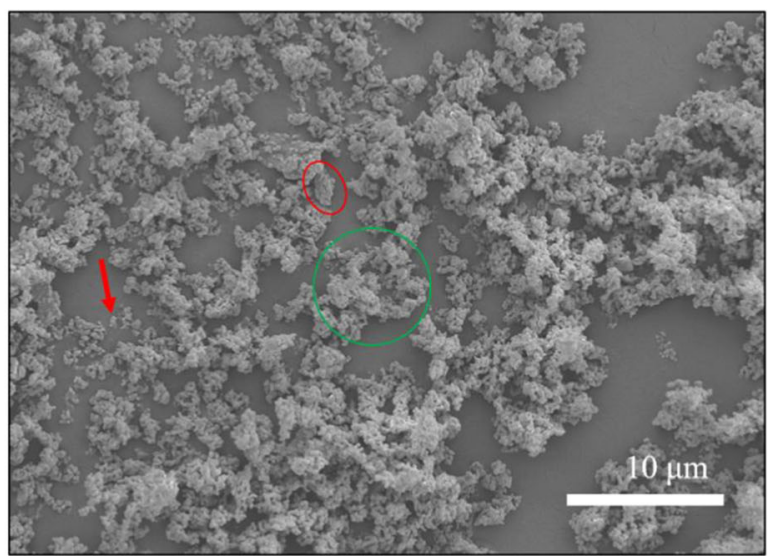

(b)

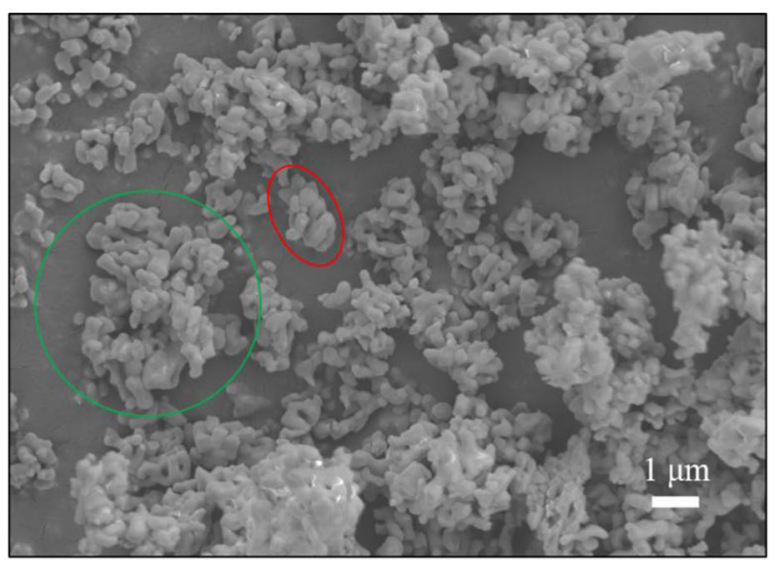

Fig. 1 SEM images of starting powder used in the study. Image (a) shows a lower magnification image of the powder with arrow indicating a single particle, red oval indicating an agglomerate, and green circle indicating a clump of agglomerates. Image (b) is a higher magnification of the powder with clump and agglomerate indicated as in (a). performed. Figure 1 shows representative SEM images of this powder at two magnifications. In Fig. 1(a), the image shows that the powder can be classified into three basic size regimes. The red arrow points to the smallest component of the powder, an individual particle, the red oval indicates particles that have become closely bound creating a more spherically shaped agglomerate, and the green circle highlights loosely bound clumps of agglomerates. Figure 1(b) is a higher magnification image of the powder. From this inspection, it can be seen that particles are irregularly shaped, less than $1 \mu \mathrm{m}$ in size, and form agglomerates that are about $1-2 \mu \mathrm{m}$ in size, hence the nominal size as specified by the manufacturer. One such agglomerate is highlighted with a red oval in Fig. 1(b), and a clump of agglomerates is indicated by the green circle. In the following sections, features of this powder that are $1 \mu \mathrm{m}$ or smaller are referred to as a "particle," larger than $1 \mu \mathrm{m}$ as an "agglomerate," and larger than $2 \mu \mathrm{m}$ as a "clump."

The powder was used to deposit a series of films onto glass substrates with thicknesses ranging between 1 and $10 \mu \mathrm{m}$. The substrate was set into motion at $0.65 \mathrm{~mm} / \mathrm{sec}$ at a working distance of $7.5 \mathrm{~mm}$, and six passes were completed for all the depositions. Figure 2 shows cross-sectional SEM images of these films. Figure 2(a) and (b) shows images of cleaved films. In Fig. 2(a), a film can be seen that is about $10 \mu \mathrm{m}$ thick. The film appears well compacted and only a few dark regions that are interpreted as pores are present in the film. There is no evidence of particles or agglomerates remaining like those seen in Fig. 1(a). Figure 2(b) shows a higher magnification image of the film of Fig. 2(a). Due to the cleaving process, the film edge is not in the same plane as the substrate edge. This is evident by the lack of focus at the substrate in the image. As a consequence, the image shows the cleaved surface at an angle. At this angle, several features that indicate agglomerate impact and flattening onto the surface, i.e. a "splat", can be seen. One such feature is highlighted with a red oval in the image. Note that the shadow below the splats indicates that the splats have pulled away from the surface. It is estimated from the image that these splats are about $1.5-4.5 \mu \mathrm{m}$ in breadth and about $0.5 \mu \mathrm{m}$ in thickness. In Fig. 2(c) and (d), cross-sectional SEM images prepared using a slow-speed diamond saw (Buehler, Bluff, IL, USA) and subsequent ion milling (Gatan PIPS II, AMTEK Inc., Pleasanton, CA, USA) are shown. In these images, a red trace is included to distinguish the true edge of the film with the out-of-focus top surface of the film. In Fig. 2(c), the film appears with many more dark regions than in Fig. 2(a); however, the flattened and layered morphology is similar to the splat structures appearing in Fig. 2(b). The length of 142 pores in this image was measured, and it was found that $93 \%$ are less 
(a)

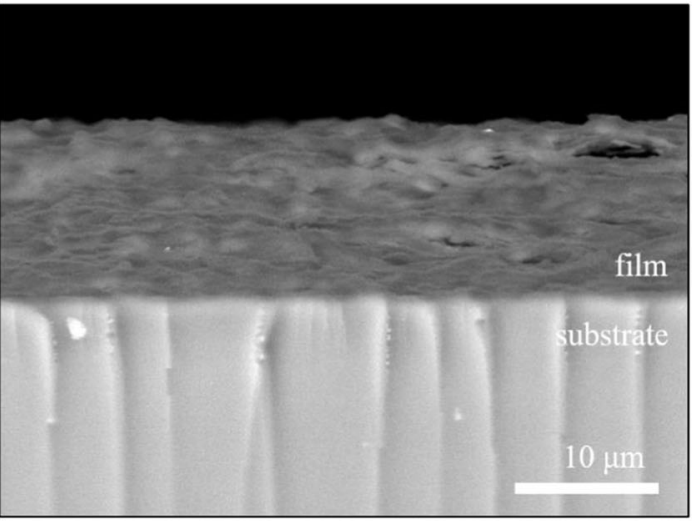

(b)
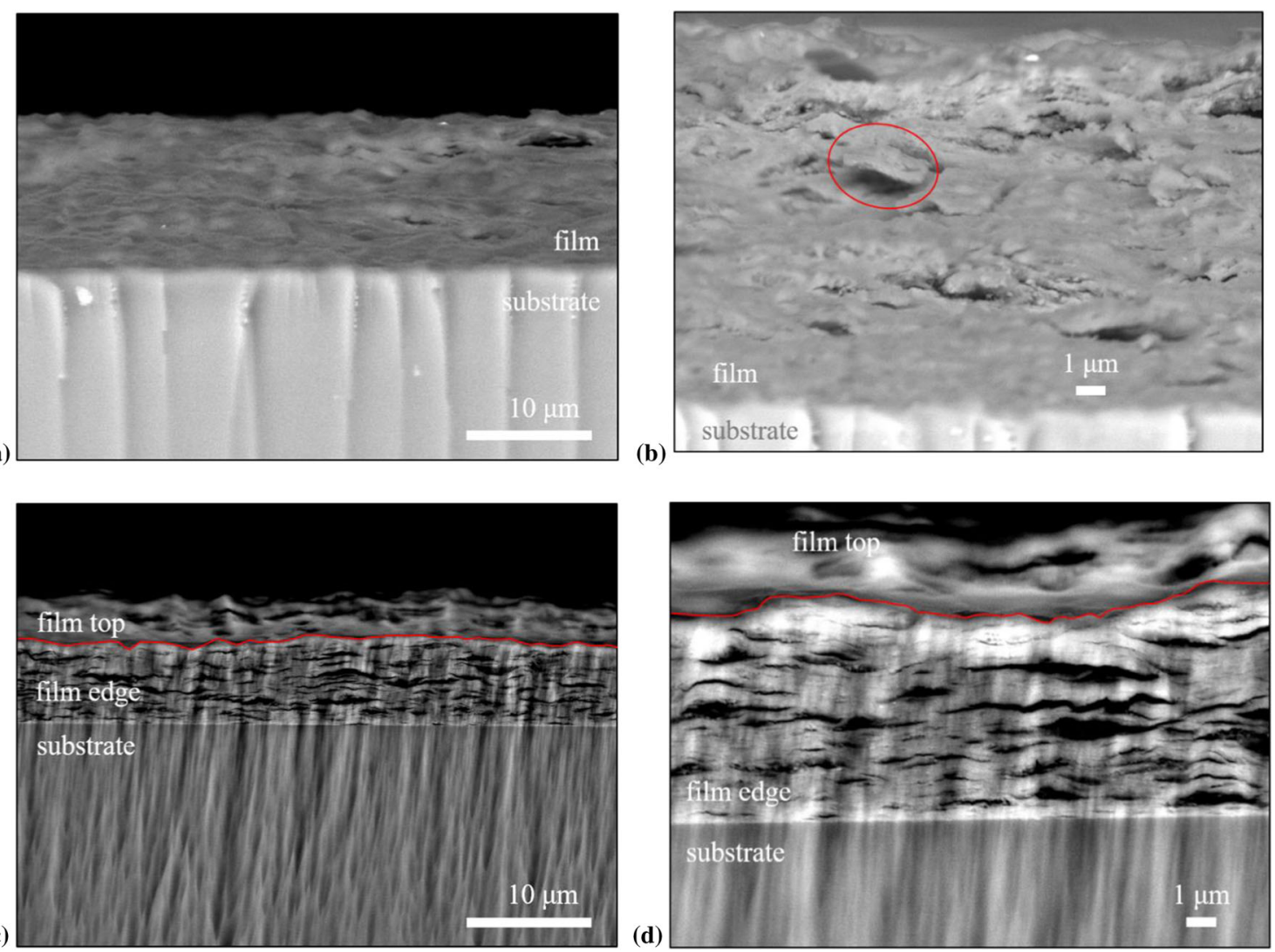

(d)

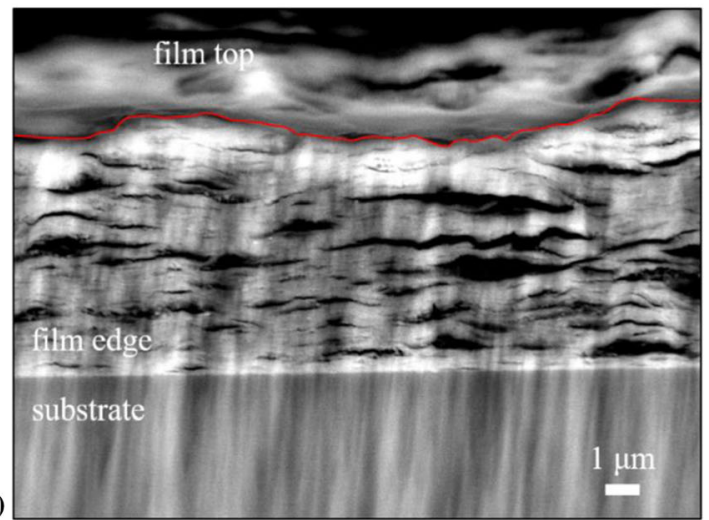

Fig. 2 SEM cross-sectional images of alumina films deposited onto glass. Images (a) and (b) show a cleaved film with splat structures lifted away from surface. Images (c) and (d) show sawed and ion-milled film edge revealing porous structure.

than $2.7 \mu \mathrm{m}$ in length. An additional ten pores were measured that had lengths greater than $2.6 \mu \mathrm{m}$, with the largest being $7.9 \mu \mathrm{m}$. These pore sizes are consistent with the size of the lifted splats above in Fig. 2(b). From this image, porosity of the film can be estimated by taking the fraction of pore (dark) area across the edge surface (region between substrate and red line). In doing this, it is estimated that about $18 \%$ of the edge is comprised of pores, i.e. the film is about $82 \%$ of full density. Note that there has not been a significant effort to refine the process here to produce a near-fully dense film as that is outside the scope of this work.

Figure 2(d) shows a magnified image of the film in Fig. 2(c). Many dark, porous regions exist between the highly dense layers within the film. Seventy-six pores in this image were measured, and it was found that $93 \%$ of these pores are less than $2.7 \mu \mathrm{m}$ in length. Five pores that were measured had lengths greater than $2.6 \mu \mathrm{m}$, with the largest pore being $7.1 \mu \mathrm{m}$.

Figure 3 shows XRD spectra from the loose powder at top and the film below with peaks indexed to the $\mathrm{Al}_{2} \mathrm{O}_{3}$ corundum structure $\mathrm{R}_{3}^{-} \mathrm{c}$, based on Rietveld refinement. Both powder and film show the similarities in peak location

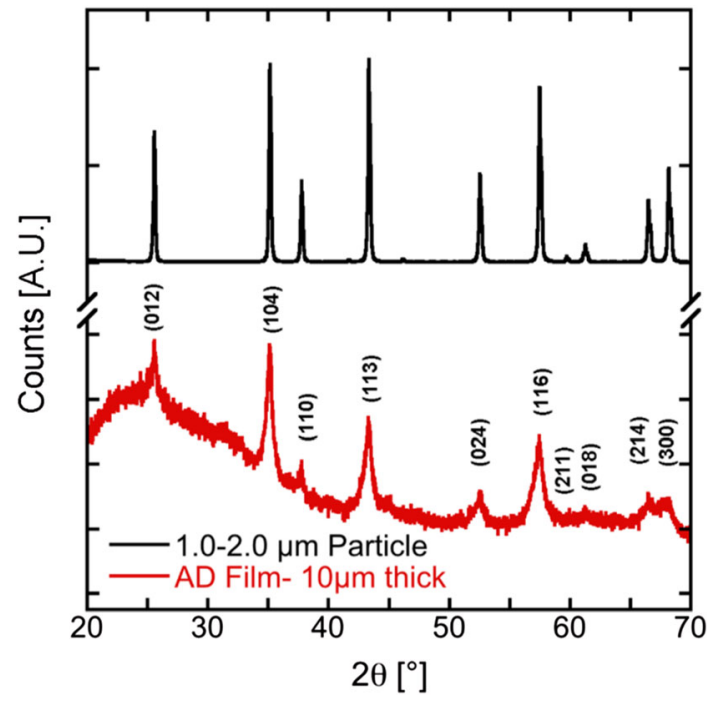

Fig. 3 XRD spectra of powder (top) and film deposited on glass (bottom) with peaks indexed to $\mathrm{Al} 2 \mathrm{O} 3$ structure.

and relative intensity, indicating no additional structural phases or lattice distortion are present. Using the Scherrer equation, we estimate the crystallite size to be $80-110 \mathrm{~nm}$ for the powder and $12 \mathrm{~nm}$ for the film. The broad hump in 
the film spectra below $40^{\circ}$ is due to amorphous reflections from the glass substrate.

\section{Particle Impact Study}

To better investigate the effect of individual particle impacts, the same powder described above was used, but the $\mathrm{AD}$ system was reconfigured to generate a more controlled and rarified particle flow to the substrate. To achieve this, a high-speed pneumatic valve, controlled by LabVIEW software, was fitted in-line between the carrier gas source and the AC. The deposition system setup and runtime parameters were set the same as above; however, during the run, the pneumatic gas inlet valve was closed by default, i.e. no gas or powder passed into the deposition chamber until an operator command opened the valve briefly to allow gas to flow. This burst of gas flow pushed a small amount of powder through the AD system resulting in only a small amount of powder flowing to the substrate. For results reported here, the substrate was set into motion at $0.65 \mathrm{~mm} / \mathrm{s}$, the inlet valve was opened for $1 \mathrm{~ms}$ every $1 \mathrm{~s}$, and only a single pass was completed. This process was repeated for substrates of microscope glass slides, alumina plates, rolled copper metal thick foils, stainless steel foils (302/304 ANN), and silicon carbide plate. The results in this work are shown for alumina impacted onto stainless steel for later comparison with computational models.

(a)

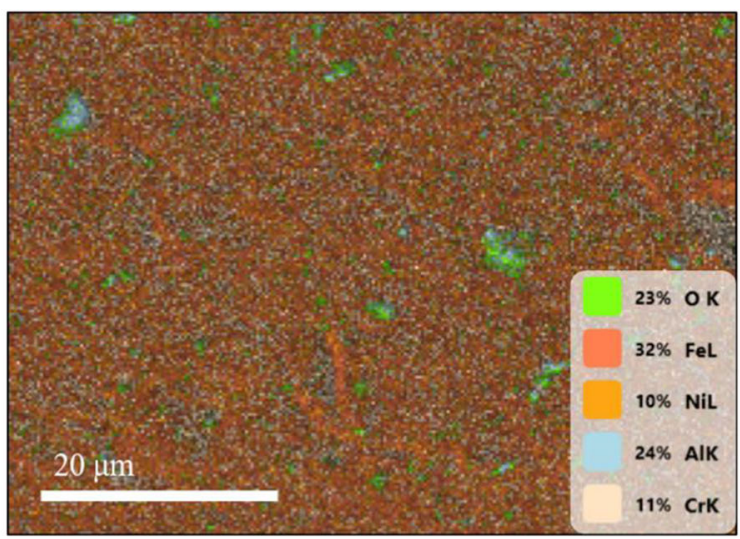

(d)
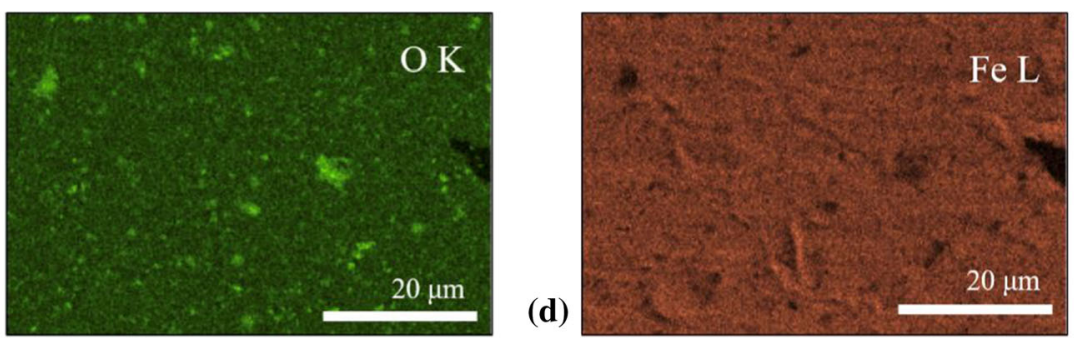

Fig. 4 EDS (a) and SEM (b) images of rarified particle impacts onto stainless steel. The legend indicates the color map of elements present on the surface. The lower row images are filtered to reveal (c) O K, (d) Fe L, and (e) Al K.
Figure 4 shows a top-view SEM image and EDS maps of an impact region on stainless steel. The SEM image (Fig. 4b) shows a surface with darker regions that correspond to impacts onto the surface. The corresponding composite image of the elements found on the surface is shown in Fig. 4(a) with the legend indicating the color map and elemental percentages. The percentages given in the inset indicate that about $53 \%$ of the surface is stainless steel $(\mathrm{Fe}, \mathrm{Ni}$, and $\mathrm{Cr}$ ) and the remaining $47 \%$ is $\mathrm{Al}$ and $\mathrm{O}$. However, it should be noted that some amount of oxygen should be attributed to the stainless steel. Figure 4(c) and (d) shows selective elemental maps of $\mathrm{Al}, \mathrm{Fe}$, and $\mathrm{O}$. From these images, it is evident that many of the dark regions in the SEM and the bright blue/green areas on the composite map correspond to alumina impact and adhesion. Figure 5 shows the SEM and EDS map for a selected large impacted region containing alumina. In the SEM image (Fig. 5b), it can be seen that the impacted region is about $2 \mu \mathrm{m}$ in diameter and contains smaller fragments present at its center. The presence of particles in this region, as well as its size, suggests that this feature is a result of an agglomerate impact. The composite EDS image in Fig. 5(a) indicates a large amount of $\mathrm{O}$ and $\mathrm{Al}$ is coincident with the impacted region, and the selective EDS maps (Fig. 5c, d, e) further confirm that this impact is comprised of $\mathrm{Al}$ and $\mathrm{O}$, suggesting that an agglomerate of about $2 \mu \mathrm{m}$ impacted and adhered to the substrate.

(b)

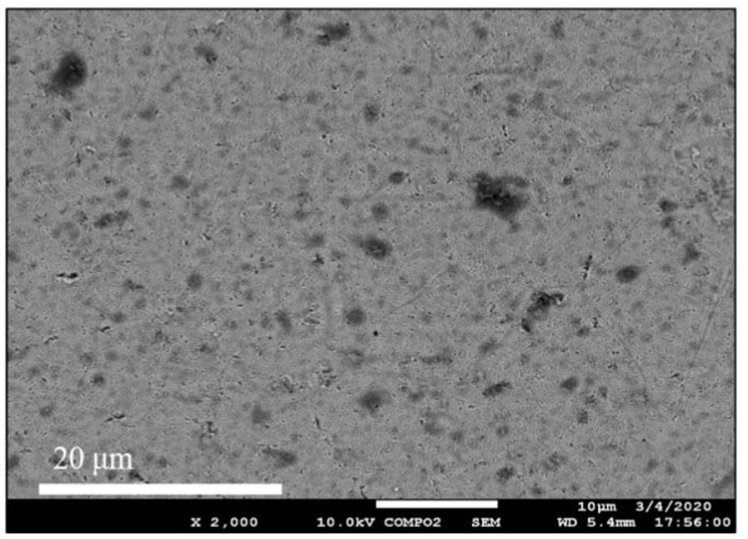

(e)

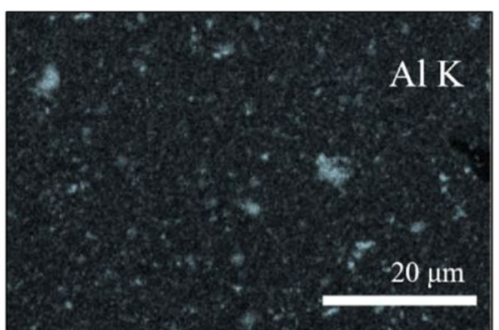


(a)

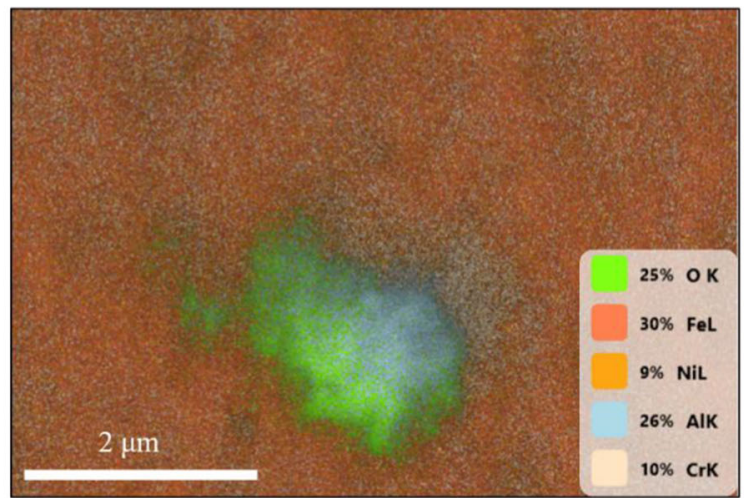

(b)

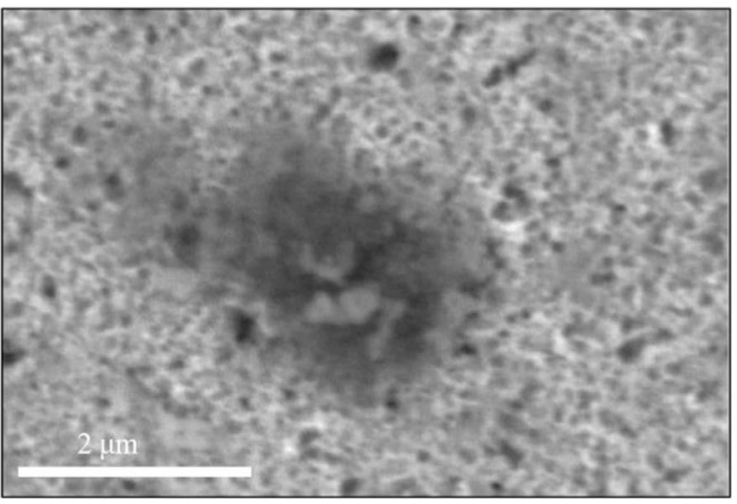

(c)

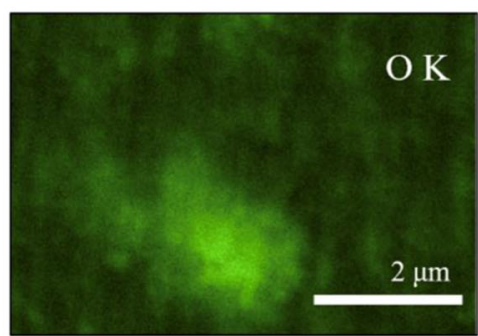

(d)

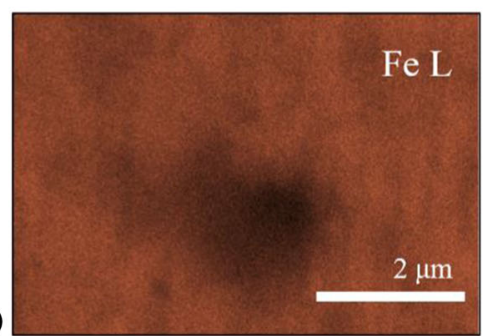

(e)

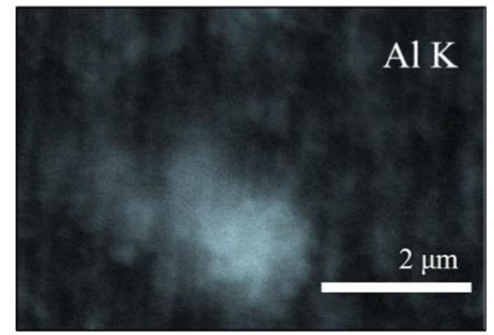

Fig. 5 EDS (a) and SEM (b) images of a single splat feature on stainless steel. The legend indicates the color map of elements present on the surface. The lower row images are filtered to reveal (c) O K, (d) Fe L, and (e) Al K.

\section{Particle Flow Analysis}

NRL is developing an in-house general-purpose CFD framework named JENRE ${ }^{\circledR}$, initially built for jet-noise calculations (Ref 39) and extended for doing multiphase and viscous flows. The JENRE ${ }^{\circledR}$ AD code is capable of doing both one-way and two-way coupling between the gas-phase and particles for dispersed-phase flow fields. For this work, one-way coupling is assumed between the particles and gas phase, where the particle loading is small enough that the particles have a negligible effect on the gas phase. Because of this, the gas-phase flow field is solved first without the presence of particles. Once the gas-phase flow field is computed, particles are tracked from the channel into the deposition chamber using a Lagrangian particle tracking procedure. Splitting the computation into two parts, a gas-phase calculation and a particle-phase calculation, enables a large number of particle simulations without recomputing the gas phase. An explicit validation has not been conducted for the particular setup used, but the particle drag laws in the flow regime being analyzed have been extensively studied and verified to be accurate. The simplifying assumptions made here serve as a starting point for simulations, and in the future, these assumptions will be relaxed and a validation will be performed on the modified model. Future studies will also include the effect of two-way coupling on the AD process.

\section{Solution Procedure}

A discontinuous Galerkin-based algorithm has recently been implemented for the JENRE ${ }^{\circledR}$ framework (Ref 40). The DG algorithm uses separate polynomial representations of the solution for each cell and is allowed to be discontinuous between cells. Facial interface conditions are used to link the cells together. This provides for a compact representation of the conservation equation fluxes for higher order solutions, and a straightforward path for generating these representations. For this article, stationary grids and an explicit Runge-Kutta time-matching algorithm are utilized. For unaligned shocks and discontinuities occurring within cells, this version of the JENRE® solver implements Hartmann shock-capturing (Ref 41), which ensures monotonicity at shocks and sharp features. The JENRE $^{\circledR}$ DG solver has been shown to produce superior results compared to earlier results (Ref 42) and has been optimized to run on GPU clusters efficiently using domain decomposition through the ParMETIS library (Ref 43) and fine-grained parallelism through the Thrust library (Ref 44) with the CUDA back end. Current simulations are done mainly on a GPU cluster available at NRL. For the tracked particles and droplets, the fourth-order Adams-Bashforth and Adams-Moulton predictor-corrector schemes are used for the temporal integration. 


\section{AD Gas-Phase Simulations}

The gas-phase simulations are based on the geometry of the NRL AD system described above. Simulations were accomplished for a two-dimensional domain that included both the deposition chamber (DC) and the channel between the AC and DC. The nozzle is positioned over the center of the substrate, creating a symmetry plane such that only half of the domain needs to be computed. An unstructured mesh was created using the Gmsh 4.0 mesh generator (Ref 45). The overall domain is shown in Fig. 6(a), and a close-up of the region of interest between the nozzle exit in the DC and the deposition surface of the substrate is shown in Fig. 6(b).

The channel is $220.87 \mathrm{~mm}$ long and $2.475 \mathrm{~mm}$ high, with a specified resolution of $0.5 \mathrm{~mm}$. At the end of the channel is a nozzle with a simple linear constriction. The length of the nozzle is $4.83 \mathrm{~mm}$ and the throat height is $0.205 \mathrm{~mm}$. The resolution at the throat is specified as $0.05 \mathrm{~mm}$. The substrate is placed $10 \mathrm{~mm}$ from the throat exit and is $7.5 \mathrm{~mm}$ high and $0.4 \mathrm{~mm}$ thick, with a resolution of $0.1 \mathrm{~mm}$. The substrate is attached to a backplate that is $29.5 \mathrm{~mm}$ high and $4.2 \mathrm{~mm}$ thick. The entire deposition chamber is $325 \mathrm{~mm}$ in length and $60.45 \mathrm{~mm}$ in height and begins $143.5 \mathrm{~mm}$ upstream of the substrate. In areas away from the region of interest, the resolution goes down to $5 \mathrm{~mm}$. The resulting mesh for the $10 \mathrm{~mm}$ standoff distance has 53,931 triangle cells and 28,261 points. Each solution took about $2.2 \mathrm{~h}$ on 16 GeForce RTX 2080 Ti's. The main plume was stable and steady, with small oscillations appearing off of the top end of the substrate. For boundary conditions, total pressure and temperature are specified at the left end of the channel. No slip, adiabatic conditions are enforced on all surfaces, and a far-field boundary condition is imposed at the exhaust. The far-field boundary is based on a characteristic representation. If the flow is supersonic exiting the domain, values at the boundary are extrapolated from the interior. If the flow is subsonic, the back pressure is used to specify the incoming characteristic and outgoing characteristics are extrapolated from the interior. The no-slip conditions along the channel wall create a uniform parabolic flow through the channel that chokes at the nozzle creating a supersonic plume. The structure and shape of the plume are consistent with earlier results (Ref 13) and result in flow that is extremely fast, but also at extremely low pressure and temperature. A curved shock wave is formed due to interaction with the substrate and backplate, as the flow is pushed upward around the backplate and to the exit plane. Results for the $10 \mathrm{~mm}$ standoff distance and 660 mbar upstream total pressure, 1.33 mbar exit plane pressure are shown in Fig. 7.

\section{AD Particle-Tracking Simulations}

Because of the assumption of one-way coupling, the particle field is computed separately from the gas-phase field, allowing us to examine a wide parameter range in a straightforward manner. After the gas-phase solution is computed, a series of particle simulations are computed to investigate the dependence of particle size on impact location and velocity. Each particle simulation tracks $1,048,576\left(2^{20}\right)$ particles at a specified particle size. Every particle is initialized at $x=215.1 \mathrm{~mm}$, or $10.6 \mathrm{~mm}$ ahead of the nozzle throat in the channel. The first ten particles are distributed uniformly from the centerline to the channel wall at $y=2.475 \mathrm{~mm}$, and then the rest of the particles are distributed randomly along the y-axis within the channel (between $y=0$ and $y=2.475 \mathrm{~mm}$ ). The particles are initialized at the gas-phase velocity and temperature and then
Fig. 6 AD gas-phase simulation showing the total domain (a) and region of interest (b).
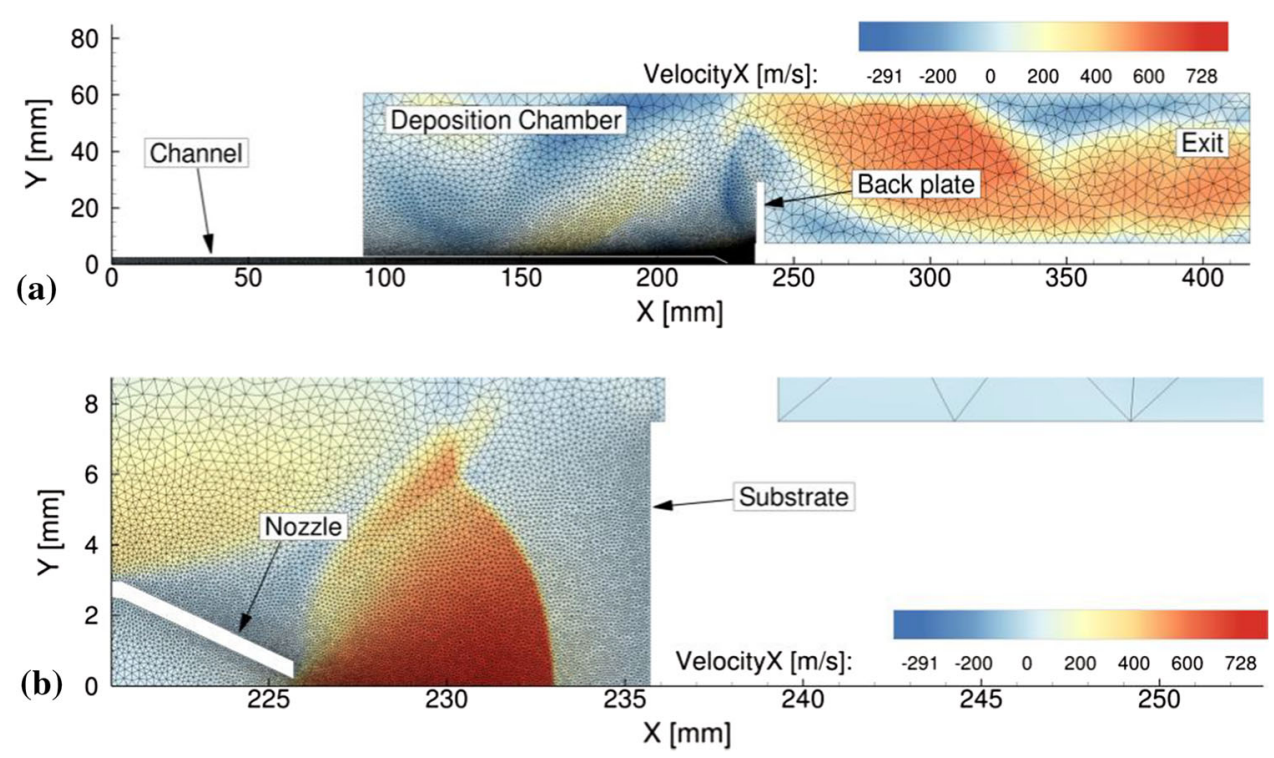
Fig. 7 Gas-phase flow-field solution for $10 \mathrm{~mm}$ standoff distance, 660 mbar total pressure case. Back pressure at exit is 1.33 mbar. Contours correspond to (a) pressure, (b) temperature, (c) axial velocity, and (d) transverse velocity.
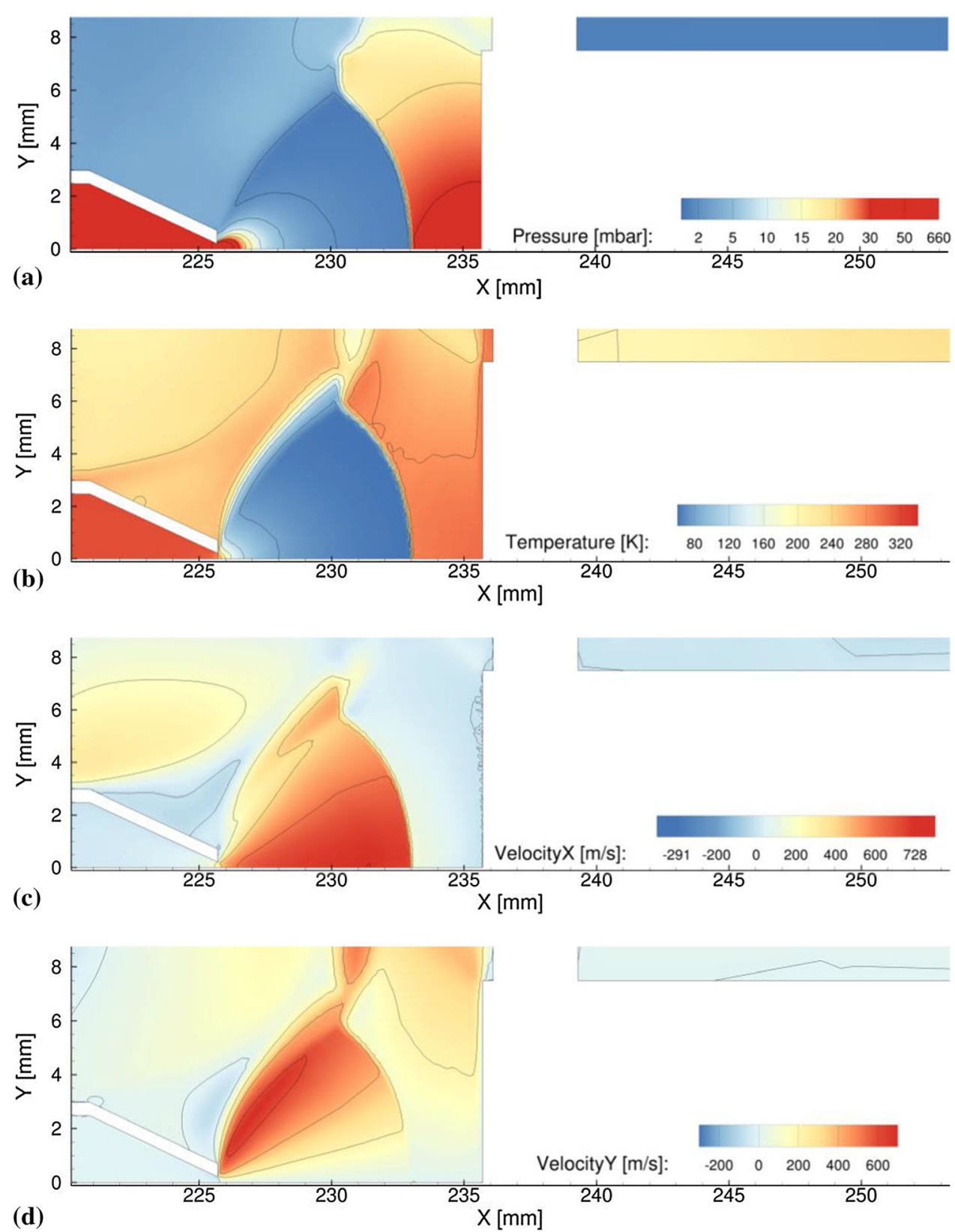

tracked as they propagate through the nozzle and impinge on the substrate or are carried further downstream and possibly exit the domain. Some particles hit the nozzle wall, some hit the substrate, some miss the substrate but hit the backplate or deposition chamber walls, some exit the domain, and a few get bound into vortices that form in the flow away from any of the boundaries. Statistics are collected on the particles that hit the substrate to determine the location, normal and tangential velocities. The particle tracking simulation is trivially parallelized to run over several processors and is typically run on four nodes on a local supercomputer (64 CPU cores total). The particle simulation time takes between $7 \mathrm{~min}$ and $17 \mathrm{~min}$ to compute, depending on whether all the particles impinged on the substrate, or whether they were carried away from the substrate and either exited the domain or became bound up in a vortex.

Five different sizes were examined for the $10 \mathrm{~mm}$ standoff distance, $0.25,0.50,0.75,1.00$, and $2.00 \mu \mathrm{m}$ particles. All of the particles are spherical in shape for the simulation and have a density of $3950 \mathrm{~kg} / \mathrm{m}^{3}$. To collect the desired statistics, the substrate is separated into 75 subsamples, each $0.1 \mathrm{~mm}$ in length. At the end of the particle simulation, the particles that hit each subsample are collected, and the particle distribution on the substrate surface is calculated, as well as the average normal and 
tangential velocity of the particles for each of the subsamples. The particle distribution is shown in Fig. 8 for each of the different particle sizes. This shows the spread from the nozzle center for particles of a specific size impacting the substrate. Two things are shown very clearly on this figure. First, as was shown in previous work (Ref 13), no particles at size $0.5 \mu \mathrm{m}$ or below hit the substrate. This cutoff appears sharp, where $100 \%$ of $0.75 \mu \mathrm{m}$ particles exiting the nozzle hit the substrate, no $0.5 \mu \mathrm{m}$ particles hit the substrate. Furthermore, most of the particles, especially at the larger sizes, have very little spread over the substrate. The bulk fall within $1.5 \mathrm{~mm}$ of the center of the substrate, even for the smaller sized particles. There also appears to be a large cluster that impacts the substrate at the outer limit of the particle size distribution. The outer peak (around $2 \mathrm{~mm}$ for $2 \mu \mathrm{m}$ particles, $2.5 \mathrm{~mm}$ for $1 \mu \mathrm{m}$ particles, and $3 \mathrm{~mm}$ for $0.75 \mu \mathrm{m}$ particles) is due to the different trajectory that particles take near the channel and nozzle walls. These particles get bound up in the strong
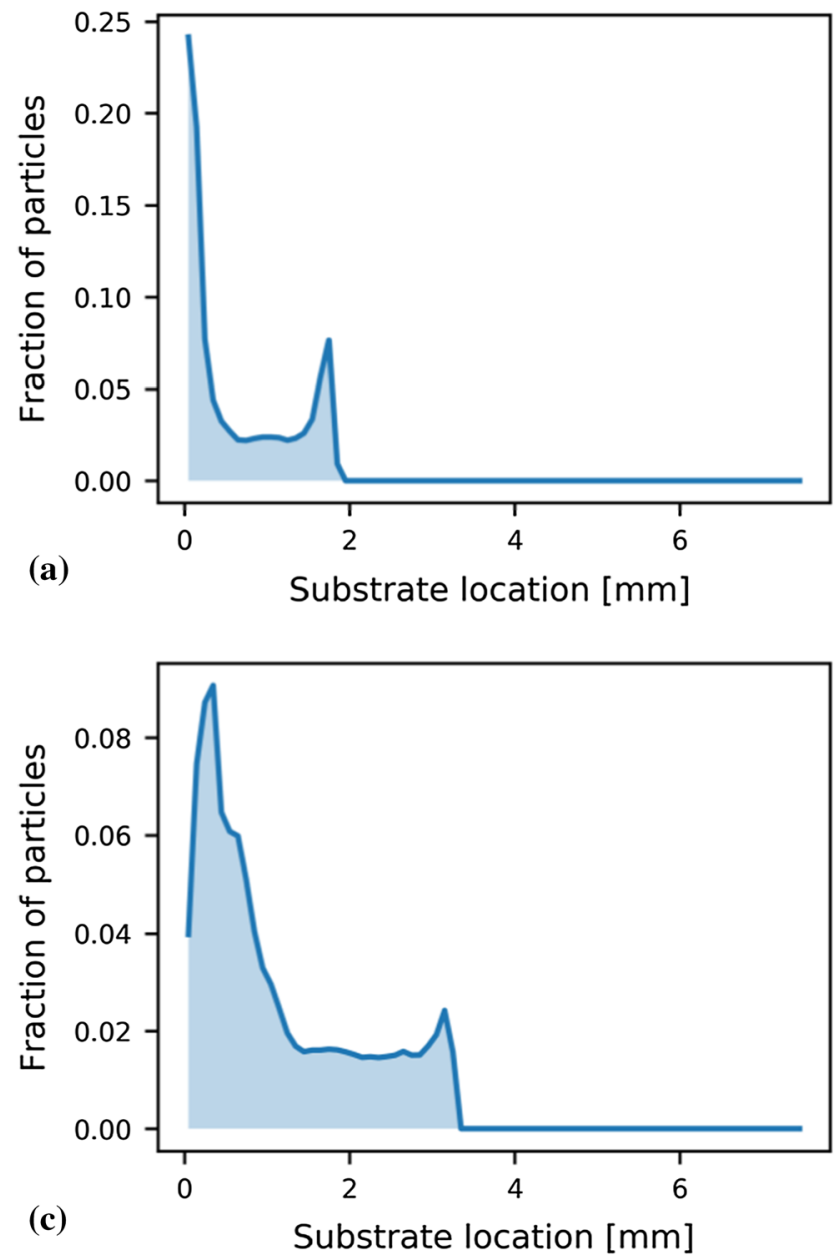

Fig. 8 Distribution of particles hitting substrate for $10 \mathrm{~mm}$ standoff distance, 660 mbar total pressure case. Back pressure at exit is 1.33 mbar. Location is measured from the center of the substrate. Curves transverse expansion of the flow just outside of the nozzle as shown in Fig. 7(c) and (d).

Figure 9 shows the average impact velocities for the particles hitting the substrate. For the larger particles, most of the momentum remains in the axial component, even for particles on the outer part of the deposition envelope. The velocity magnitude remains very consistent for each particle size over the substrate surface. For 1 and $2 \mu \mathrm{m}$ particles, most of the velocity is in the normal direction independent of where the particle strikes the substrate. For the $0.75 \mu \mathrm{m}$ particle, the particle normal velocity varies from around $145 \mathrm{~m} / \mathrm{s}$ near the center of the substrate to around $100 \mathrm{~m} / \mathrm{s}$ at $3 \mathrm{~mm}$ from the centerline. These velocities are lower than previous results due to using the Keyes viscosity law instead of assuming a constant viscosity for the gas through the expanding plume (Ref 46). For comparison, constant-viscosity particle-tracking simulations resulted in normal velocities for $1 \mu \mathrm{m}$ particles of $300-350 \mathrm{~m} / \mathrm{s}$ and for $0.75 \mu \mathrm{m}$ particles of $150-250 \mathrm{~m} / \mathrm{s}$.
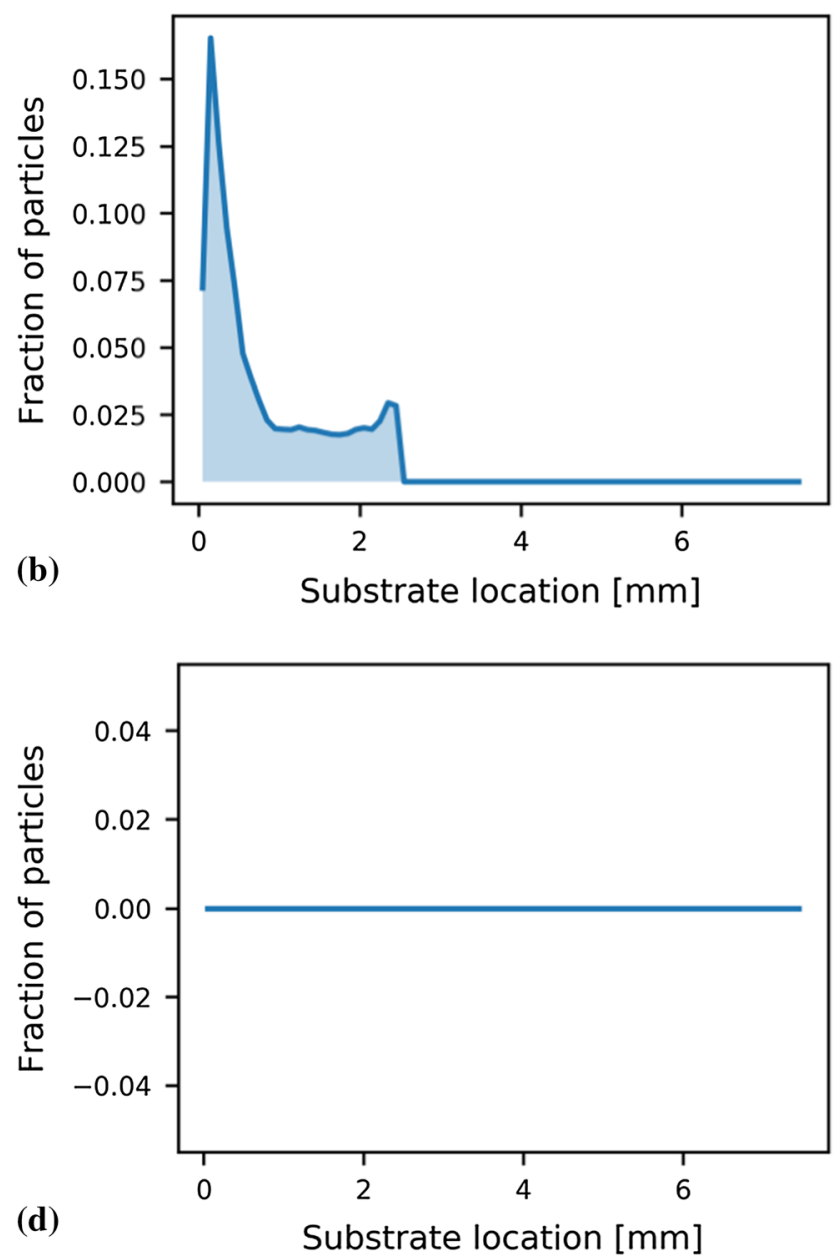

correspond to (a) $2 \mu \mathrm{m}$ particles, (b) $1 \mu \mathrm{m}$ particles, (c) $0.75 \mu \mathrm{m}$ particles, and (d) $0.5 \mu \mathrm{m}$ particles. 

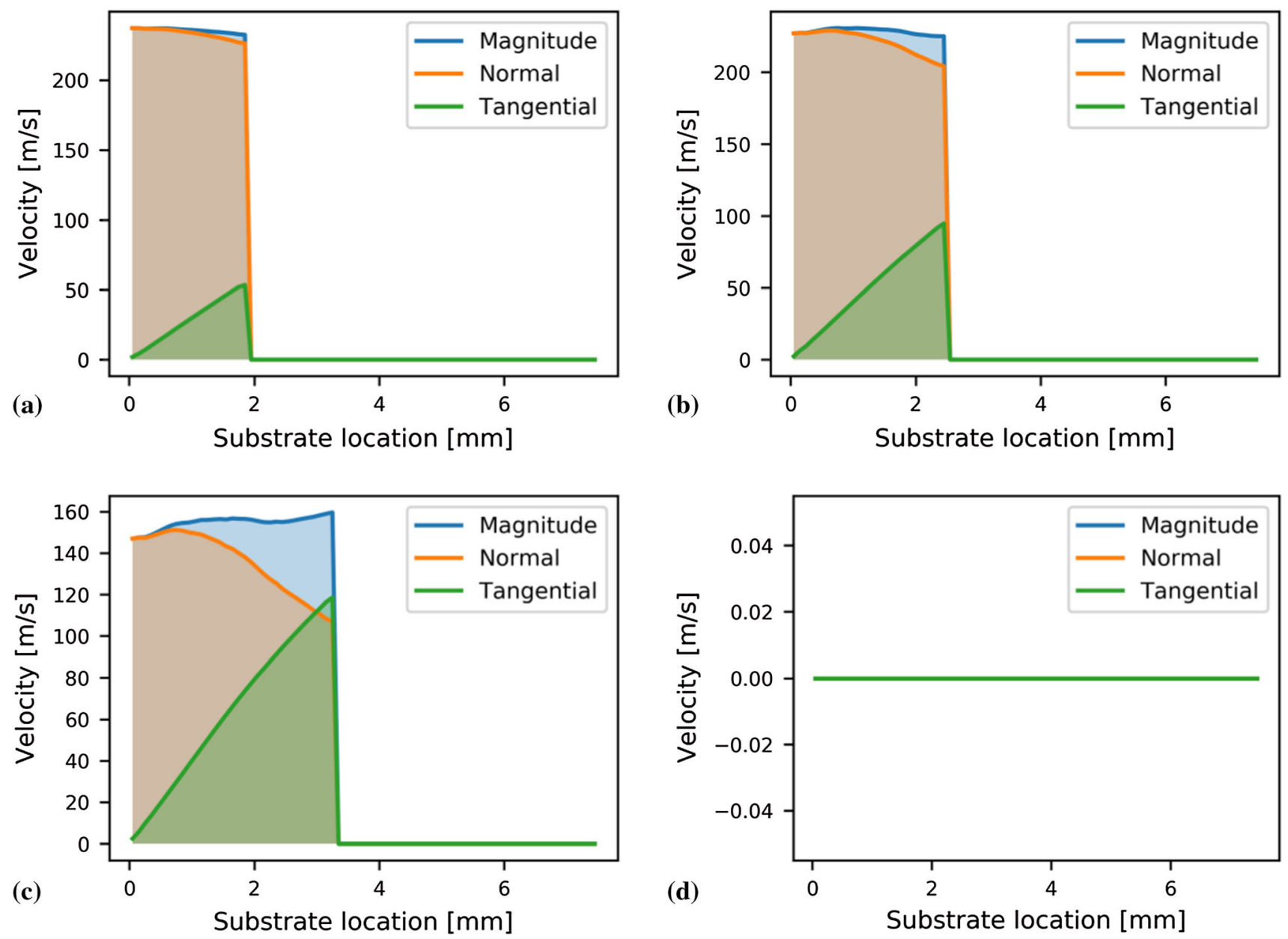

Fig. 9 Average impact velocity of particles hitting the substrate. Location is measured from the center of the substrate. Figures correspond to (a) $2 \mu \mathrm{m}$ particles, (b) $1 \mu \mathrm{m}$ particles, (c) $0.75 \mu \mathrm{m}$ particles, and (d) $0.5 \mu \mathrm{m}$ particles.

\section{Particle Impact Analysis}

As previously discussed, the large deformation and fracture behavior of high velocity, brittle particle impacts in the $\mathrm{AD}$ process make many simulation tools infeasible. In this work, an Eulerian solver is adapted as it is able to account for all of the desired physics (Ref 47). The shock physics code CTH is used to simulate both a 2-D and 3-D model of AD particle impacts. CTH is software developed by Sandia National Laboratories that is designed to handle shock wave propagation and extreme material deformation in an Eulerian reference frame (Ref 48). The 2-D model implemented in this work is used for a parametric study, while the 3-D model is used to study oblique and multiparticle impacts. Both models are shown in Fig. 10. In the 2-D case, the model is axisymmetric to simplify the model and reduce its computational burden. Both models are parameterized similarly with semi-infinite (also called absorbing or transmitting) exterior boundary conditions applied to the substrate and outflow boundary conditions applied elsewhere. Semi-infinite conditions are implemented so that mechanical waves in the substrate do not influence the behavior of the particle-substrate interface. The particle in both cases is assumed spherical and the substrate is made large enough such that the boundaries are sufficiently far from any particle or substrate fracturing behavior. A mesh convergence study was performed on both models resulting in run times for the 2-D model of 1-3 h (25 ns simulation time) on a 144-processor SGI ICE-X cluster, and 1-2 $\mathrm{h}$ for the 3-D model on a similar cluster with 216 processors.

The parametric study using the 2-D model consisted of varying the substrate material, particle material, and particle size and impact velocity, then assessing adhesion by determining a critical (stationary) velocity where the particle remains partially intact while at the same time not rebounding from the substrate. The time history of this process is illustrated by Fig. 11, showing the initial impact of an $\mathrm{Al}_{2} \mathrm{O}_{3}$ particle onto an $\mathrm{Al}_{2} \mathrm{O}_{3}$ substrate followed by particle fracture, which increases the rate of particle deceleration, and finally a stationary particle (i.e. zero 


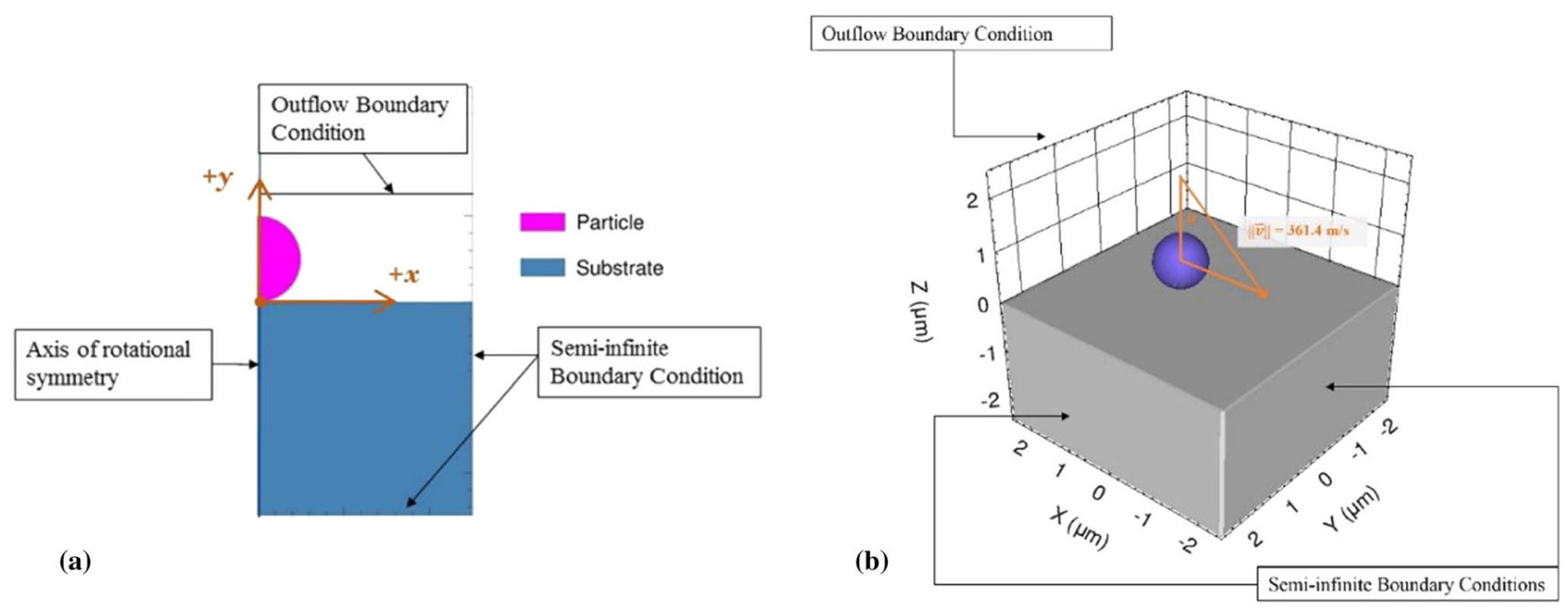

Fig. 10 (a) 2-D and (b) 3-D finite element models used in this work with boundary conditions applied to each surface.

Fig. 11 Deformation time history of an $\mathrm{Al}_{2} \mathrm{O}_{3}$ particle onto an $\mathrm{Al}_{2} \mathrm{O}_{3}$ substrate from initial impact to a stationary condition of a particle impacting a substrate at the critical velocity. (a) $1 \mathrm{~ns}$, (b) $5 \mathrm{~ns}$, and (c) $25 \mathrm{~ns}$ (a)

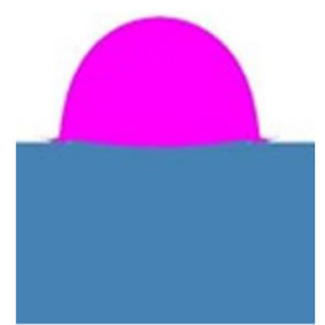

(b)

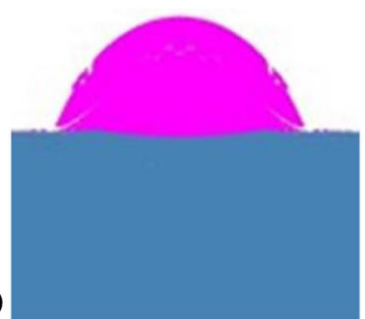

(c)

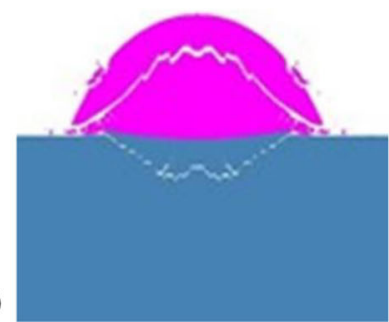

Table 1 Summary of materials and their respective constitutive models used in the parametric study. Additionally, Vickers hardness for each material is included

\begin{tabular}{lllc}
\hline \multicolumn{1}{c}{ Material } & \multicolumn{1}{c}{ Volumetric } & \multicolumn{1}{c}{ Elastic-plastic } & Vickers hardness (HV) \\
\hline Alumina (99.5\%) & Johnson-Holmquist Ceramic 2 & Johnson-Holmquist Ceramic 2 & $1900 \pm 100$ \\
Aluminum nitride & Johnson-Holmquist Ceramic 2 & Johnson-Holmquist Ceramic 2 & $1180 \pm 90$ \\
Silicon carbide & Johnson-Holmquist Ceramic 2 & Johnson-Holmquist Ceramic 2 & $2628.3 \pm 44.1$ \\
Copper & Sesame tabular & Johnson-Cook viscoplastic/fracture & $40.9 \pm 0.1$ \\
Steel 4340 & Sesame tabular & Johnson-Cook viscoplastic/fracture & 228 \\
\hline
\end{tabular}

velocity). The incoming particle velocity which results in a stationary particle (i.e. zero velocity for more than $5 \mathrm{~ns}$ of simulation time) at the end of the simulation is defined here as the critical velocity (CV). By determining the $\mathrm{CV}$ of the particle onto the substrate, the theoretical point of maximum film growth rate and ideal particle adhesion to the substrate can be found. This $\mathrm{CV}$ also determines an approximate maximum velocity that can be used to achieve successful deposition.

Five candidate materials (Table 1) were chosen as part of the parametric study, namely silicon carbide ( $\mathrm{SiC}$ ), alumina $\left(\mathrm{Al}_{2} \mathrm{O}_{3}, 99.5 \%\right.$ purity), aluminum nitride (AlN), Copper $(\mathrm{Cu})$, and steel 4340 . These materials were chosen as they exhibit a range of properties (e.g. hardness) and are consistent with some common materials used in the AD process as either a particle or a substrate (see the materials used in the previous experiments). The constitutive models used to simulate both the volumetric and elastic-plastic (including damage/fracture) behaviors of the materials are summarized in Table 1. As part of the 2-D parametric study, all five materials will be used as both a substrate and a particle. For each combination of materials, particle diameters are varied from 0.5 to $10 \mu \mathrm{m}$ and the impact velocity varied from 100 to $500 \mathrm{~m} / \mathrm{s}$ in initial increments of $50 \mathrm{~m} / \mathrm{s}$ and later increments of $10 \mathrm{~m} / \mathrm{s}$ to determine the $\mathrm{CV}$. The particle sizes and velocities encompass sizes and velocities commonly seen during the $\mathrm{AD}$ process and are 
consistent with and encompass the ranges determined above using CFD (Ref 13).

The results of the 2-D analysis to determine $\mathrm{CV}$ are shown in Table 2 . The tabular results demonstrate that most critical velocities were in the $300-400 \mathrm{~m} / \mathrm{s}$ range with a variation of $\pm 10 \mathrm{~m} / \mathrm{s}$ due to the size of the particle. Note that the constitutive model used in the work does not consider an explicit size effect; therefore, any variation in $\mathrm{CV}$ is purely due to the mass of the particle changing with the diameter. However, results did show that above $2 \mu \mathrm{m}$, the $\mathrm{CV}$ does not appear to change and could therefore represent an upper limit for deposition. Further analysis into determining an upper limit would require considering a size effect in the constitutive model and/or considering agglomerates with a defined breaking force. It can also be noted that some combinations are marked with an ' $\mathrm{X}$ ', which is used to indicate that a CV could not be found. In these instances, the particle either rebound and never achieved a stable, stationary position or the particle excessively fractured to the point which is could no longer be identified. Figure 12(a) shows a selection of particlesubstrate combinations, which produced successful deposition. Generally, these successful combinations show some fracture of both the particle and substrate but not to an excessive extent. Conversely, Fig. 12(b) shows material combinations, which did not produce successful deposition. These combinations generally consist of a behavior that shows little to no fracture of either the particle, substrate, or both. As seen by Fig. 12(b) and Table 2, this occurs mostly when using a relatively ductile material, such as those commonly used in cold spray deposition (steel, copper, etc.). Interestingly, when the substrate and particle are the same material, the simulations indicate that deposition will always be possible. This information could be used to better deposit thick films in the future. Typically, the AD process will maintain a constant pressure/velocity in the deposition chamber. However, the results presented here suggest that once an initial anchoring layer is formed, a different pressure/velocity could be used to increase the deposition efficiency. This result is consistent with the conclusions of Park et al. (Ref 49) that fracture of previously deposited particles plays an important role in the deposition of subsequent layers and changes the velocity necessary for deposition to occur.

In the 3-D study, the angle of impact, $\theta$, is varied from $2.5^{\circ}$ to $30^{\circ}$ to determine how angle of impact can affect particle adhesion. The angles chosen are derived from the results shown in Figs. 8 and 9, which suggest that incoming particles with angles higher than approximately $30^{\circ}$ do not come into contact with the substrate and are carried away by the gas flow. Having determined critical velocities for each material combination, the 3-D model is now used for a single particle-substrate combination (a $1 \mu \mathrm{m}, \mathrm{Al}_{2} \mathrm{O}_{3}$ $\mathrm{Al}_{2} \mathrm{O}_{3}$ impact such that the magnitude of the velocity vector was $361.4 \mathrm{~m} / \mathrm{s}$ ) to examine the oblique impact effect. Figure 13 shows the results of these impacts at varying angles of incidence. The results show that ideally, a normal or very low angle impact is best but fairly high deposition efficiency can be achieved up to angles of approximately $15^{\circ}$. After this point, the particle tends to substantially fragment and most of the particle does not remain in contact with the substrate. These oblique impacts are approximately what would be seen from particles impacting the substrate away from the centerline as demonstrated by the CFD results.

Up to this point, the mechanical simulations have only shown single-particle impacts and determined parameters that represent upper bounds for deposition. However, in a real deposition process, multiple particles will impact at nearly the same location. The interaction of multiple particles can substantially change how individual particles may deposit. For instance, particles that have a lower velocity than the calculated $\mathrm{CV}$, which would normally bounce off the substrate, could interact with another particle and be compacted into the final film. To demonstrate this, a 20-particle simulation was run. This simulation consists of alumina impacting alumina with particles intermittently entering the simulation. Each particle has a randomized location, velocity, and size. The location is drawn from a multivariate normal distribution with mean at the center of the substrate and standard deviation such that 99.9\% of the draws will have the entire particle within the domain. The velocity is again drawn from a normal with mean equal to the $\mathrm{CV}$ and standard deviation equal to the

Table 2 Mean critical velocity in $\mathrm{m} / \mathrm{s}$ for diameter range of each combination (particles listed in top row, substrates listed in far-left column)

\begin{tabular}{llllll}
\hline & Alumina (99.5\%) & Aluminum nitride & Silicon carbide & Copper & Steel 4340 \\
\hline Alumina (99.5\%) & $361.4 \pm 13.5$ & $181.4 \pm 3.8$ & $150 \pm 0$ & $\mathrm{X}$ & $441.4 \pm 6.9$ \\
Aluminum nitride & $335.7 \pm 7.9$ & $480.0 \pm 18.3$ & $\mathrm{X}$ & $\mathrm{X}$ & $\mathrm{X}$ \\
Silicon carbide & $334.3 \pm 9.8$ & $481.7 \pm 9.8$ & $455.0 \pm 8.4$ & $\mathrm{X}$ & $\mathrm{X}$ \\
Copper & $\mathrm{X}$ & $\mathrm{X}$ & $\mathrm{X}$ & $304.3 \pm 5.3$ & $412.9 \pm 7.6$ \\
Steel 4340 & $330.0 \pm 5.8$ & $\mathrm{X}$ & $\mathrm{X}$ & $368.6 \pm 3.8$ & $450.0 \pm 15.3$ \\
\hline
\end{tabular}


(a)

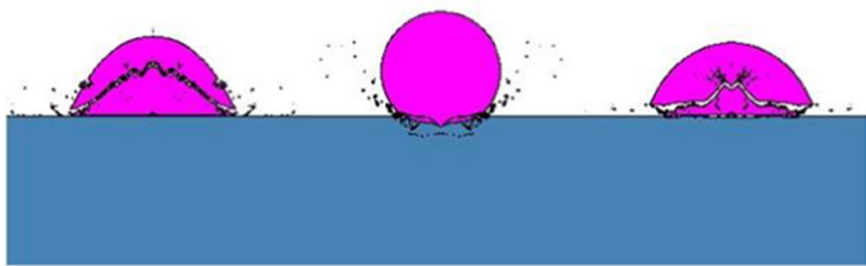

(b)

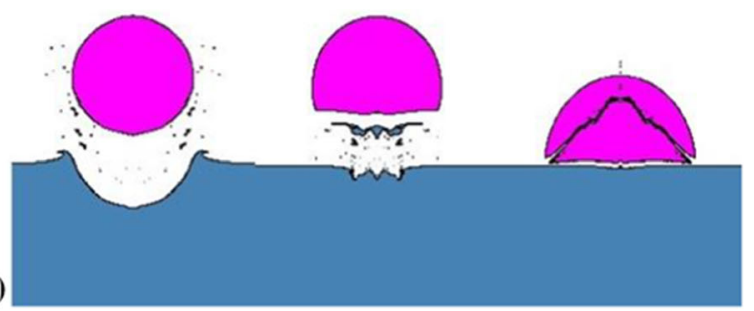

Fig. 12 Simulation results of some material combinations producing both a) successful and b) unsuccessful deposition. (a) Final deformed states of material combinations at critical velocities. From left to right: $\mathrm{Al}_{2} \mathrm{O}_{3}$ particle onto $\mathrm{SiC}$ substrate, $\mathrm{AlN}$ particle onto $\mathrm{Al}_{2} \mathrm{O}_{3}$ substrate, and AlN particle onto SiC substrate. (b) Deformation of select ductile-brittle material combinations. From left to right: $\mathrm{SiC}$ particle on $\mathrm{Cu}$ substrate, steel particle on AlN substrate, AlN particle on steel substrate

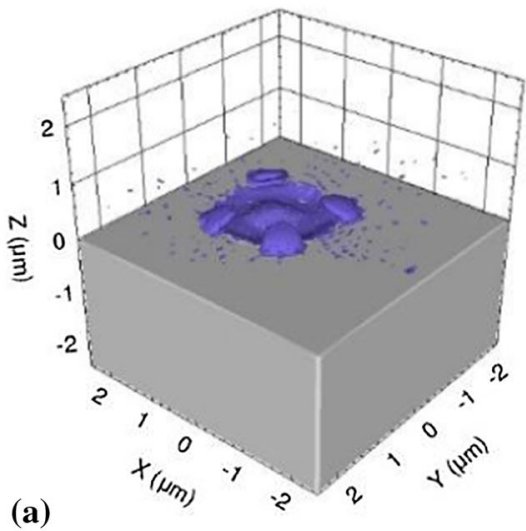

(b)

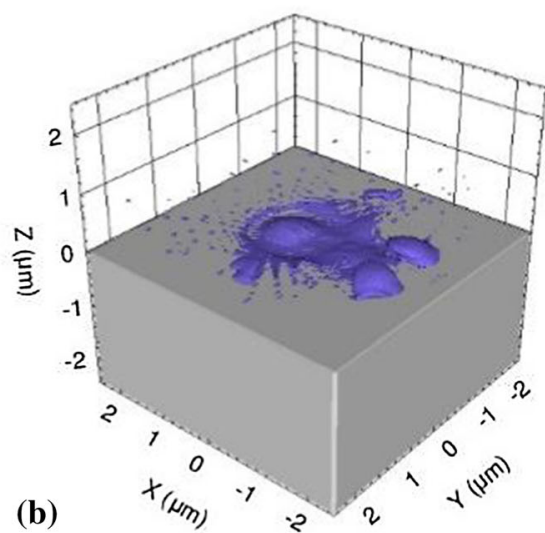

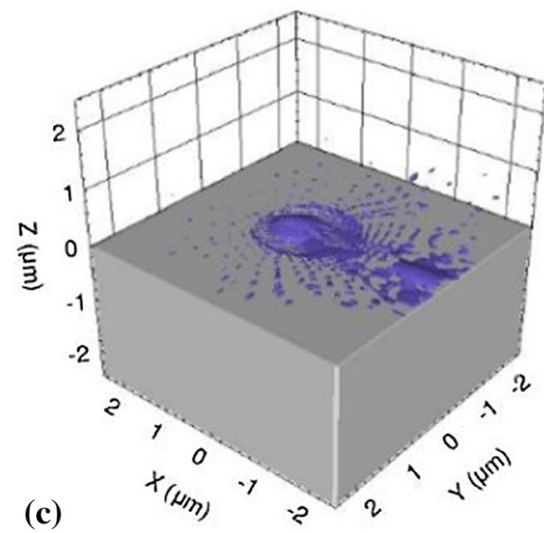

(c)

Fig. 13 Particle state after $25 \mathrm{~ns}$ for oblique impacts of (a) $2.5^{\circ}$, (b) $15^{\circ}$, and (c) $30^{\circ}$ for an $\mathrm{Al}_{2} \mathrm{O}_{3}$ particle onto an $\mathrm{Al}_{2} \mathrm{O}_{3}$ substrate.

Fig. 14 Multiparticle simulation of $20 \mathrm{Al}_{2} \mathrm{O}_{3}$ particles impacting a small area on an $\mathrm{Al}_{2} \mathrm{O}_{3}$ substrate. (a) Velocity contours of all particles at the last time step. All particles have near 0 velocity indicating adhesion and successful deposition. (b) Each particle is colored uniquely to show the particle substrate boundary as well as the extent of the fracturing of the particles after repeated impact and compaction.

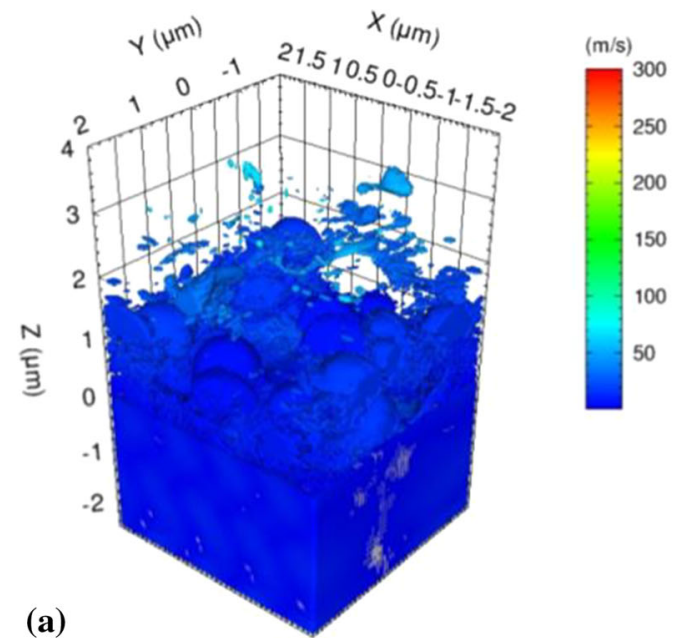

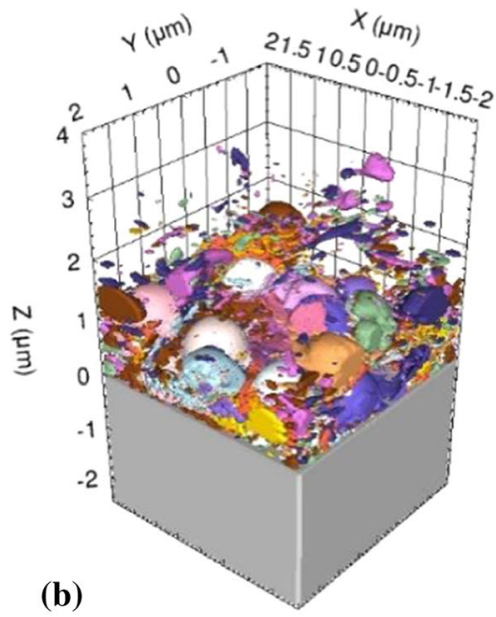

variation from Table 2. Finally, the size is drawn from a uniform distribution between 0.5 and $2 \mu \mathrm{m}$, derived from the results in the previous section. The results of the simulation are shown in Fig. 14. The velocity shown in Fig. 14(a) indicates that the film that has come to a steadystate (i.e. fixed) position with only a few small fragments having a nonzero velocity. Figure 14(b) shows each particle colored in a different color and clearly shows how the film has adhered to the substrate and how particles interactions affect the development of the film. Incoming particles, even if their velocity is above or below the $\mathrm{CV}$, tend to further compact particles that have already impacted, which gives validity to the simulations as nonconstant particle impact velocities are expected during the experimental process. The results show that a dense film has been formed that is roughly $1 \mu \mathrm{m}$ thick over an area of $16 \mu \mathrm{m}^{2}$ 
with only 20 particles. The results suggest that particle interaction plays a very important role in formation of a film. This interaction between particles, as has been shown, is potentially more significant than the velocity of individual particles in the formation and adhesion of dense films to substrates.

\section{Discussion}

Returning to the EDS images of individual impacts (Fig. 5), the distribution of particles hitting the substrate is further explored. The splat in the composite image was measured to have an area of $279 \mu^{2}$. By assuming the splat to be $0.5 \mu \mathrm{m}$ thick (based on Fig. 2b), initially spherical, and conserving volume after impact, the diameter of the incoming particle is calculated to be about $3 \mu \mathrm{m}$. This same process is applied to all of the $\mathrm{Al}$ present in the EDS map of Fig. 4 to gain insight into the size distribution of alumina impacting and adhering to the substrate. The results of performing this are shown in Fig. 15 along with the SEM and Al EDS images from Fig. 4, as well as the ImageJ threshold-limited alumina measurement results in Fig. 15(e). In this image, the $\mathrm{Al}$ appears as black patches outlined in red on a white background. One can notice that each of the images shows the same impacts but the features are most distinct in the threshold-limited image.

The areas of each of the 2432 distinct $\mathrm{Al}$ features were computed by ImageJ. The percentage of $\mathrm{Al}$ (black) measured as a fraction of the total surface (entire image) is about $16 \%$. This is considerably smaller than the $24 \%$ measured by the EDS system, so it is likely this method is underrepresenting the amount of $\mathrm{Al}$ present due to the chosen threshold values and image resolutions. In this measurement, the smallest resolvable size was 1 pixel which is equivalent to $0.014 \mu \mathrm{m}^{2}$ or an equivalent diameter of about $0.24 \mu \mathrm{m}$. The main histogram (Fig. 15a) shows the distribution of $\mathrm{Al}$ on the surface based on the equivalent diameter (bottom axis) and measured area (top axis). Based on these measurements, it appears that the majority of the adhered alumina is in the form of small particles. More than $85 \%$ of the adhered $\mathrm{Al}$ arises from particles less than
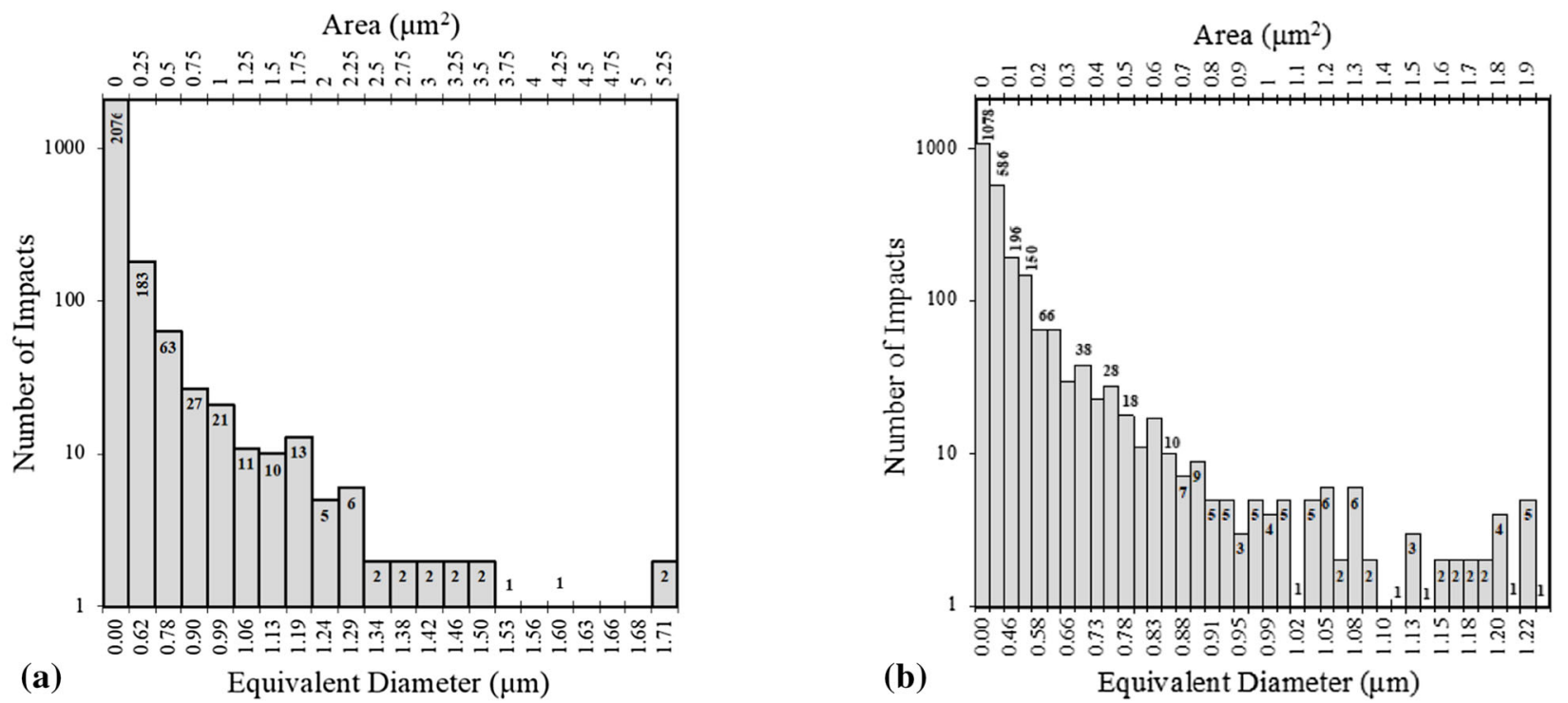

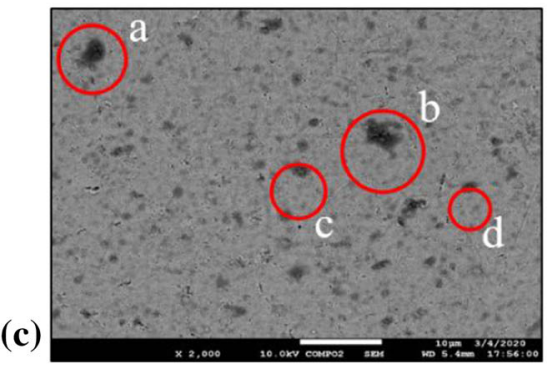

(d)

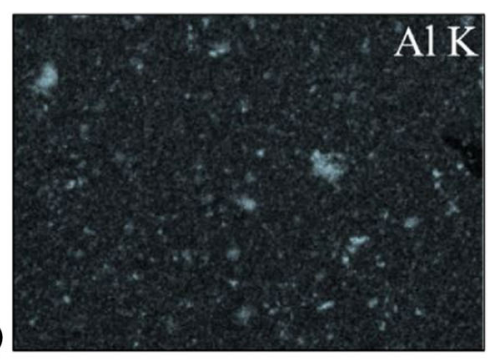

(e)

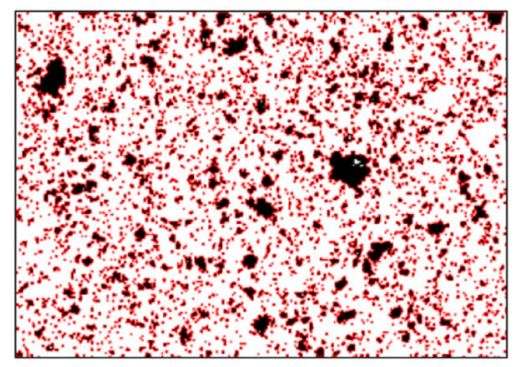

Fig. 15 (a) The histogram shows Al feature distribution on a log scale binned by area and calculated equivalent starting diameter. Likewise, the histogram (b) shows a more detailed region for equivalent diameters below $1.22 \mu \mathrm{m}$, since the majority of the data are in this size regime. The bottom row images show (c) SEM, (d) EDS of Al, and (e) high-threshold alumina measurement image of stainless steel after rarified alumina impacts. In (c), the circles a-d highlight several larger splats and are described in the text. 
$0.62 \mu \mathrm{m}$. Only three $\mathrm{Al}$ features that were larger than $1.71 \mu \mathrm{m}$ in equivalent diameter were measured. Those three features, along with one other large feature, are highlighted with red circles in the SEM image of Fig. 15(c). The feature labeled (a) had a measured area of $13.305 \mu \mathrm{m}^{2}$ with an equivalent diameter of $2.33 \mu \mathrm{m}$. Features (b), (c), and (d) were measured to be $18.564,6.68$, $3.33 \mu \mathrm{m}^{2}$ with equivalent diameters of $2.61,1.85$, and $1.47 \mu \mathrm{m}$, respectively. The detailed histogram Fig. 15(b) is a finer binned distribution of $\mathrm{Al}$ features with area less than $2 \mu \mathrm{m}^{2}$. Here, it can be seen that about $44 \%$ of the $\mathrm{Al}$ present comes from the first bin containing particles that are less than $0.36 \mu \mathrm{m}$ in equivalent diameter. While there are a few agglomerates impacting and sticking to the substrate, it appears much of the adhesion is in the form of individual particles less than about $0.62 \mu \mathrm{m}$. The presence of such small $\mathrm{Al}$ features could be a due to adhesion of small nonfracturing particles, fragmented portions of agglomerates or particles, or some form of redeposition of smaller particles near the substrate. For the particles with equivalent diameter, the assumption of a $0.5 \mu \mathrm{m}$ feature height is an overestimate, so these features would likely be even smaller. This could suggest that for alumina deposition onto stainless steel small particles take part in the deposition and film formation and/or significant fracture of impacting particles occurs.

This result is somewhat in contrast to the CFD results, but two assumptions in the CFD model can be noted which explain this discrepancy. Namely, the CFD model (as with most models) assumes spherical particles and that each particle is only a single particle, not an agglomerate. However, by re-examining Fig. 1, it can be seen that these assumptions are not strictly true. It is well understood that the shape of an object can drastically change how the flow of a gas moves around the object or how the object moves in the flow. Additionally, as will be discussed in the following paragraph, the sub- $0.5 \mu \mathrm{m}$ particle impacts seen are likely a result of tightly packed agglomerates breaking up mid-flight during the deposition process or upon impact of the agglomerate on the substrate. This mid-flight breakup could substantially change the distribution of particle sizes that impact the substrate. Computationally, both of the listed assumptions are very difficult to circumvent but will need to be revisited in a future work to achieve the most accurate representation of the $\mathrm{AD}$ process.

The observed gaps underneath the splats in Fig. 2(b) and the pore structures in Fig. 2(c) and (d) provide motivation to explore possible correlations between pore and splat size. For this discussion, it is assumed that the pore length gives an estimate of the splat length. First, some potential pitfalls in this assumption are acknowledged. It is possible that a splat could be partially adhered, so a smaller pore length would be observed resulting in an underestimate of splat size. On the other hand, multiple small splats could impact adjacent to one another and then form a larger pore than each of the individual splats, resulting in an overestimate of splat size. The latter point of adjacent splats can be addressed by close inspection of the morphology, which can give evidence of multiple splat structures. With these pitfalls addressed, the pore lengths of 142 sites in Fig. 2(c) and 76 sites in Fig. 2(d) were measured. Of those measured, $93 \%$ of the pores are less than $2.7 \mu \mathrm{m}$ in length. The equivalent starting diameter of a spherical agglomerate can be estimated using a process similar to the above process, where it is assumed the splat to be about $0.5 \mu \mathrm{m}$ in thickness (again based on Fig. 2b). In doing this, it was found that none of the pores measured could have resulted from an agglomerate larger than $2 \mu \mathrm{m}$ in diameter. This is consistent with the 1-2 $\mu \mathrm{m}$ size of the agglomerates found in Fig. 1(a), which was found by CFD results and reported by the company. It suggests that clumps of particles are effectively broken up during impact or transport to the substrate. An explanation for pore formation due to agglomerates could be explained by excessive kinetic energy remaining in the agglomerate after impact that provides some amount of rebound from the surface. The large number of pores in these current films then could suggest that much of the deposition taking place is due to these agglomerates. On the other hand, the smallest pores measured were in excess of $0.2 \mu \mathrm{m}$, giving the lower bound on a pore-producing particle size of $0.58 \mu \mathrm{m}$. This suggests impacting alumina with a size range between 0.58 and $2 \mu \mathrm{m}$ was responsible for producing porosity. This is consistent with the CFD results.

To compare the impact study with the film deposition, it is noted that all the pores observed in Fig. 2 were larger than $0.2 \mu \mathrm{m}$ (equivalent dia. of $0.56 \mu \mathrm{m}$ ). It can also be noted that $81 \%$ of the observed $\mathrm{Al}$ splats present in the EDS image are $0.56 \mu \mathrm{m}$ or smaller. This is a consistent picture with the overall density measurement of $80 \%$ and suggests that small single particles of alumina give rise to fully dense film while larger particles and agglomerates create pores in the film.

The final comparison of this work uses the CFD model to inform the FE model and then compare those results to the experimental observations. As with the experiments, a simulation of a single alumina particle on steel in 3D was conducted with results shown Fig. 16. The simulation has assumed that the alumina particle is $1 \mu \mathrm{m}$, based on the CFD modeling, and had a $300 \mathrm{~m} / \mathrm{s}$ velocity normal to the substrate. The velocity chosen is slightly lower than the CV determined above but is approximately the midpoint between the CFD- and FE-derived velocities. Analyzing the simulation impact, the diameter of the residual impacted particle is roughly $1.3 \mu \mathrm{m}$, which is on the higher side of the results shown in Fig. 15 but a reasonably similar 

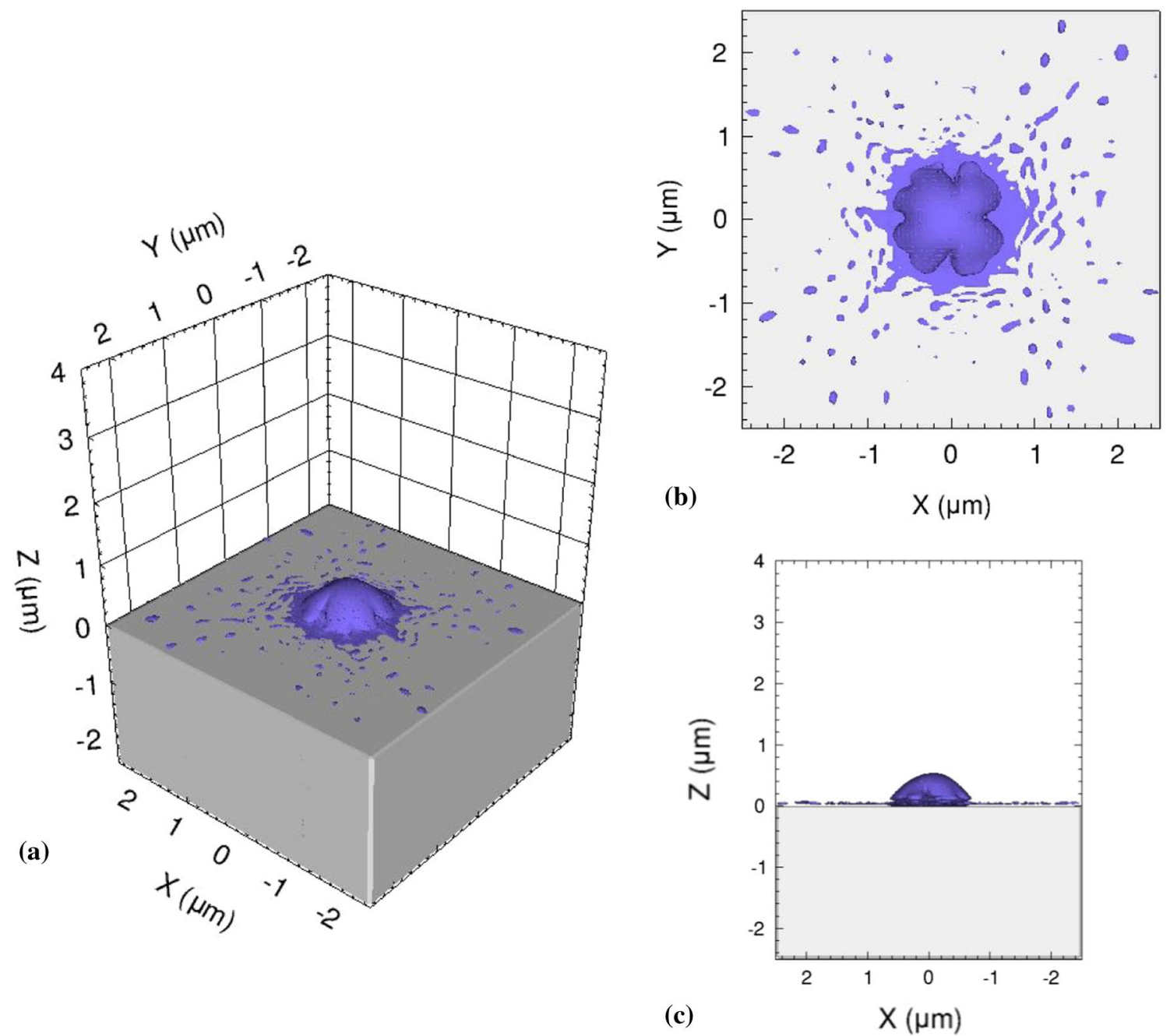

Fig. 16 Single-particle impact simulation of alumina onto steel for comparison with experimental results. The particle has an initial size of $1 \mu \mathrm{m}$ and velocity of $300 \mathrm{~m} / \mathrm{s}$ normal to the substrate. Comparison with experiments shows good quantitative and qualitative results.

result. Returning to the SEM images of Fig. 2(b) again, the height of the particle is roughly $0.5 \mu \mathrm{m}$, which is nearly identical to the height of the impacted particle in Fig. 16(c). Qualitatively, Fig. 16(a) can also be compared to Fig. 5 and by doing so, similar trends are present. The differences in the two images appear to be mostly due to the angle of impact, where in the FE model, the impact was normal, and in the experiment, there appears to be a slightly oblique impact. It is also noteworthy that in Fig. 16 there are a large number of small fragmented particles present on the substrate. This could also explain the large number of very small particles found in the EDS image in Fig. 15. If this is indeed the case, it provides a consistent picture with CFD results. That is, particles (or agglomerates) greater than $0.75 \mu \mathrm{m}$ impact the substrate. The impact not only fractures the particle, but also produces a large number of small fragments. These results lend credibility and validity to the simulations developed and demonstrate the potential effectiveness of using a coupled CFD/FE approach for predicting the AD process.

As noted above, the FE models predict certain combinations of particles and substrates do not result in a CV being found. However, some of these combinations have been used in previous experiments and have been successfully deposited. In the $2 \mathrm{D}$ simulation, only a single particle was implemented so the packing and consolidation mechanisms suggested in the literature, and by the multiparticle results here, for film growth are not active as there are no other incoming particles. Additionally, the shape of the particle and possible agglomerate breaking, thus removing some of the kinetic energy in the system, is not considered in the FE model and will potentially have a significant effect on the predictions. In any case, by establishing that there is no CV between two materials with single-particle impacts, the simulation does not suggest that film growth will not be possible; rather, it implies that growth may not be ideal. For 
instance, it is known that alumina can be deposited onto copper and the simulations here suggest that the initial layer of alumina onto copper may not result in the strongest bond (i.e. no critical velocity was established) between the film and substrate or may result in a lower efficiency of initial film growth. If the idea of packing and consolidation is combined with the result of Table 2 that a material will always be able to deposit onto itself, then it can be said that once the initial layer is established and packed, film growth should occur with relative ease. Information, such as that derived here, can be used a priori to suggest combinations of materials that will deposit well from the initial layer as well as materials which have a lower chance for successful deposition. Additionally, the results derived can be used to modify the deposition process in situ so that an initial layer is formed using one set of parameters (to achieve a desired particle velocity) and then those parameters are modified once the initial layer is established and the particles are being deposited onto a layer of similar material. The process parameter-particle velocity relationship would require an inverse solution from the FE model through the CFD model to determine but could result in very high efficiency deposition.

The biggest potential of the established framework is to construct process parameter envelopes as well as optimal parameter prediction for experiments. This type of parameter envelope development is common in other manufacturing areas, such as metal additive manufacturing. The CFD model developed in this work is able to determine, based on particle material and size, whether a particle will impact the substrate as well as the velocity at which it will impact the substrate. Using this information, given a material and some geometric parameters that are fixed in the experiment, a curve representing the lower limit for particle size and AC pressure among other parameters could be established. Likewise, the FE model developed in this work could be used to establish upper limits on parameters such as particle velocity, which is directly related to the input pressure and particle size and material. Additionally, as has been mentioned, using an inverse approach by combining the FE model with the CFD model could be used to determine a truly optimal process parameter selection. This type of inverse model would likely require statistical surrogates and/or other machine learning techniques but the models established in this work have the capability to generate the required data to support such an effort.

\section{Conclusions}

This work has shown the development of a self-consistent approach to understanding the AD process using combined CFD, FE, and experimental efforts. Deposition was first performed on a trial set of materials. This included analysis of both the powder and resulting film. Next, the experimental parameters were used to inform a CFD model, which simulated the possible flight path of particles of varying sizes. These results were quantified in a probabilistic sense to demonstrate where the majority of particles impacted the substrate, giving information about their impact angle and velocity. Additionally, the flow field obtained using the given parameter set was analyzed. Finally, the results of the CFD modeling were used to inform an FE modeling effort. FE model results demonstrated some limitations in possible material choices, how impact angle can affect adhesion, and how multiple particles interact to form a film. The terminus of this work used a fixed set of parameters and materials to demonstrate the efficacy of the self-consistent framework and was able to show, quantitatively and qualitatively, that the framework is effective at predicting the AD process, even though it still has some limitations such as idealized particle shape and lack of agglomeration considerations.

A number of possible uses for this framework were discussed. First, the framework could be used as it stands to a priori determine the efficacy of deposition given a set of parameters being considered. Secondly, the framework could be used as a method to determine process windows on a per material basis to inform future studies of process parameters that work best and those that may not result in a successful deposition. Finally, the framework could be used in a machine learning or surrogate modeling implementation so that truly optimal parameters could be selected using an inverse/optimization approach.

Acknowledgments The authors acknowledge the support of the Office of Naval Research (ONR) through the Naval Research Laboratory's (NRL) Basic Research Program. This work was also supported in part by a grant of computer time from the DOD High Performance Computing Modernization Program at the Air Force Research Laboratory (ARFL) DOD Supercomputing Recourse Centers (DSRC). RS acknowledges the significant contributions of Rachael Osborne and Tyler Martin during their time at NRL.

Open Access This article is licensed under a Creative Commons Attribution 4.0 International License, which permits use, sharing, adaptation, distribution and reproduction in any medium or format, as long as you give appropriate credit to the original author(s) and the source, provide a link to the Creative Commons licence, and indicate if changes were made. The images or other third party material in this article are included in the article's Creative Commons licence, unless indicated otherwise in a credit line to the material. If material is not included in the article's Creative Commons licence and your intended use is not permitted by statutory regulation or exceeds the permitted use, you will need to obtain permission directly from the copyright holder. To view a copy of this licence, visit http://creativecommons. org/licenses/by/4.0/. 


\section{References}

1. J. Akedo, M. Ichiki, K. Kikuchi, and R. Maeda, Jet Molding System for Realization of Three-Dimensional Micro-Structures, Sensors Actuators, A Phys. 1998.

2. D.-M. Chun and S.-H. Ahn, Deposition Mechanism of Dry Sprayed Ceramic Particles at Room Temperature Using a NanoParticle Deposition System, Acta Mater., Acta Materialia Inc., 2011, 59(7), p 2693-2703.

3. S.D. Johnson, E.R. Glaser, S.F. Cheng, and J. Hite, Dense Nanocrystalline Yttrium Iron Garnet Films Formed at Room Temperature by Aerosol Deposition, Mater. Res. Bull., 2016.

4. T. Kagotani, R. Kobayashi, S. Sugimoto, K. Inomata, K. Okayama, and J. Akedo, Magnetic Properties and Microwave Characteristics of Ni-Zn-Cu Ferrite Film Fabricated by Aerosol Deposition Method, J. Magn. Magn. Mater., 2005, 290-291, p 1442-1445.

5. Y. Kato, S. Sugimoto, and J. Akedo, Magnetic Properties and Electromagnetic Wave Suppression Properties of Fe-Ferrite Films Prepared by Aerosol Deposition Method, Jpn. J. Appl. Phys., 2008.

6. D. Hanft, J. Exner, M. Schubert, T. Stöcker, P. Fuierer, and R. Moos, An Overview of the Aerosol Deposition Method: Process Fundamentals and New Trends in Materials Applications, $J$. Ceram. Sci. Technol., 2015, 182, p 147-182.

7. J. Akedo, Room Temperature Impact Consolidation (RTIC) of Fine Ceramic Powder by Aerosol Deposition Method and Applications to Microdevices, J. Therm. Spray Technol., 2008, 17(2), p 181-198.

8. R.C. Dykhuizen and M.F. Smith, Gas Dynamic Principles of Cold Spray, J. Therm. Spray Technol., 1998.

9. A. Papyrin, V. Kosarev, S. Klinkov, A. Alkhimov, and V.M. Fomin, "Cold Spray Technology," Cold Spray Technology, 2007.

10. H. Katanoda, M. Fukuhara, and N. Iino, Numerical Simulation on Impact Velocity of Ceramic Particles Propelled by Supersonic Nitrogen Gas Flow in Vacuum Chamber, Mater. Trans., 2007, 48(6), p 1463-1468.

11. D.M. Chun, J.O. Choi, C.S. Lee, and S.H. Ahn, Effect of Standoff Distance for Cold Gas Spraying of Fine Ceramic Particles $(<5 \mu \mathrm{m})$ under Low Vacuum and Room Temperature Using Nano-Particle Deposition System (NPDS), Surf. Coatings Technol., Elsevier B.V., 2012, 206(8-9), p 2125-2132.

12. J.J. Park, M.W. Lee, S.S. Yoon, H.Y. Kim, S.C. James, S.D. Heister, S. Chandra, W.H. Yoon, D.S. Park, and J. Ryu, Supersonic Nozzle Flow Simulations for Particle Coating Applications: Effects of Shockwaves, Nozzle Geometry, Ambient Pressure, and Substrate Location upon Flow Characteristics, J. Therm. Spray Technol., 2011, 20(3), p 514-522.

13. S.D. Johnson, D. Schwer, D.S. Park, Y.S. Park, and E.P. Gorzkowski, Deposition Efficiency of Barium Hexaferrite by Aerosol Deposition, Surf. Coatings Technol., Elsevier, 2017, 332(September), p 542-549.

14. M. Grujicic, C.. Zhao, W.. DeRosset, and D. Helfritch, Adiabatic Shear Instability Based Mechanism for Particles/Substrate Bonding in the Cold-Gas Dynamic-Spray Process, Mater. Des., 2004, 25(8), p 681-688.

15. S. Yin, X. Wang, W. Li, and B. Xu, Numerical Investigation on Effects of Interactions Between Particles on Coating Formation in Cold Spraying, J. Therm. Spray Technol., 2009, 18(4), p 686-693.

16. F. Meng, H. Aydin, S. Yue, and J. Song, The Effects of Contact Conditions on the Onset of Shear Instability in Cold-Spray, $J$. Therm. Spray Technol., 2015, 24(4), p 711-719.

17. S. Yin, X. Wang, W. Li, H. Liao, and H. Jie, Deformation Behavior of the Oxide Film on the Surface of Cold Sprayed
Powder Particle, Appl. Surf. Sci., Elsevier B.V., 2012, 259, p 294300.

18. W.Y. Li, K. Yang, S. Yin, and X.P. Guo, Numerical Analysis of Cold Spray Particles Impacting Behavior by the Eulerian Method: A Review, J. Therm. Spray Technol., 2016, 25(8), p 1441-1460.

19. M. Grujicic, B. Pandurangan, W.C. Bell, M. Daqaq, L. Ma, N. Seyr, M. Erdmann, and J. Holzleitner, A Computational Analysis and Suitability Assessment of Cold-Gas Dynamic Spraying of Glass-Fiber-Reinforced Poly-Amide 6 for Use in Direct-Adhesion Polymer Metal Hybrid Components, Appl. Surf. Sci., 2008, 254(7), p 2136-2145.

20. W.-Y. Li, H. Liao, C.-J. Li, G. Li, C. Coddet, and X. Wang, On High Velocity Impact of Micro-Sized Metallic Particles in Cold Spraying, Appl. Surf. Sci., 2006, 253(5), p 2852-2862.

21. W.-Y. Li and W. Gao, Some Aspects on 3D Numerical Modeling of High Velocity Impact of Particles in Cold Spraying by Explicit Finite Element Analysis, Appl. Surf. Sci., 2009, 255(18), p 78787892.

22. J. Xie, D. Nélias, H. Walter-Le Berre, K. Ogawa, and Y. Ichikawa, Simulation of the Cold Spray Particle Deposition Process, J. Tribol., 2015, 137(4), p 041101

23. W.-Y. Li, S. Yin, and X.-F. Wang, Numerical Investigations of the Effect of Oblique Impact on Particle Deformation in Cold Spraying by the SPH Method, Appl. Surf. Sci., 2010, 256(12), p 3725-3734.

24. T. Wang, C. Begau, G. Sutmann, and A. Hartmaier, Large Scale Molecular Dynamics Simulation of Microstructure Formation during Thermal Spraying of Pure Copper, Surf. Coatings Technol., Elsevier B.V., 2015, 280, p 72-80.

25. H. Assadi, H. Kreye, F. Gärtner, and T. Klassen, Cold SprayingA Materials Perspective, Acta Mater., Elsevier Ltd, 2016, 116, p 382-407.

26. W.Y. Li, D.D. Zhang, C.J. Huang, S. Yin, M. Yu, F.F. Wang, and H.L. Liao, Modelling of Impact Behaviour of Cold Spray Particles: Review, Surf. Eng., 2014, 30(5), p 299-308.

27. J. Akedo, Aerosol Deposition of Ceramic Thick Films at Room Temperature: Densification Mechanism of Ceramic Layers, $J$. Am. Ceram. Soc., 2006, 89(6), p 1834-1839.

28. H. Park, J. Kwon, I. Lee, and C. Lee, Shock-Induced Plasticity and Fragmentation Phenomena during Alumina Deposition in the Vacuum Kinetic Spraying Process, Scr. Mater., Acta Materialia Inc., 2015, 100, p 44-47.

29. H. Kwon, Y. Kim, J. Kim, H. Seok, D. Kim, and C. Lee, Bonding Formation in Vacuum Kinetic-Sprayed Y2O3 Particles Induced by High-Velocity Impact, Surf. Coatings Technol., Elsevier, 2020, 394(May), p 125866.

30. F. Li, J. Pan, and C. Sinka, Modelling Brittle Impact Failure of Disc Particles Using Material Point Method, Int. J. Impact Eng., Elsevier Ltd, 2011, 38(7), p 653-660.

31. B. Daneshian and H. Assadi, Impact Behavior of Intrinsically Brittle Nanoparticles: A Molecular Dynamics Perspective, J. Therm. Spray Technol., 2014, 23(3), p 541-550.

32. P. Sarobol, M. Chandross, J.D. Carroll, W.M. Mook, D.C. Bufford, B.L. Boyce, K. Hattar, P.G. Kotula, and A.C. Hall, Room Temperature Deformation Mechanisms of Alumina Particles Observed from In Situ Micro-Compression and Atomistic Simulations, J. Therm. Spray Technol., Springer US, 2016, 25(1-2), p 82-93.

33. D. Hanft, P. Glosse, S. Denneler, T. Berthold, M. Oomen, S. Kauffmann-Weiss, F. Weis, W. Häßler, B. Holzapfel, and R. Moos, The Aerosol Deposition Method: A Modified Aerosol Generation Unit to Improve Coating Quality, Materials (Basel)., 2018.

34. J. Exner, M. Schubert, D. Hanft, J. Kita, and R. Moos, How to Treat Powders for the Room Temperature Aerosol Deposition 
Method to Avoid Porous, Low Strength Ceramic Films, J. Eur. Ceram. Soc., 2019.

35. S.D. Johnson, E.R. Glaser, S. Cheng, F.J. Kub, and C.R. Eddy, Characterization of As-Deposited and Sintered Yttrium Iron Garnet Thick Films Formed by Aerosol Deposition, Appl. Phys. Express, 2014, 7(3), p 035501.

36. S.D. Johnson, F.J. Kub, and C.R. Eddy, ZnS/Diamond Composite Coatings for Infrared Transmission Applications Formed by the Aerosol Deposition Method, Wind. Dome Technol. Mater. XIII, 2013, 8708, p 87080T.

37. S.D. Johnson, E.R. Glaser, F.J. Kub, and C.R. Eddy, Formation of Thick Dense Yttrium Iron Garnet Films Using Aerosol Deposition, J. Vis. Exp., 2015.

38. C.A. Schneider, W.S. Rasband, and K.W. Eliceiri, "NIH Image to ImageJ: 25 Years of Image Analysis," Nature Methods, 2012.

39. J. Liu, A. Corrigan, K. Kailasanath, R. Ramammurti, N. Heeb, D. Munday, and E. Gutmark, "Impact of Deck and Jet Blast Deflector on the Flow and Acoustic Properties of Imperfectly Expanded Supersonic," 51st AIAA Aerospace Sciences Meeting including the New Horizons Forum and Aerospace Exposition 2013, 2013.

40. A. Corrigan, A.D. Kercher, and D.A. Kessler, A Moving Discontinuous Galerkin Finite Element Method for Flows with Interfaces, Int. J. Numer. Methods Fluids, 2019, 89(9), p 362-406.

41. R. Hartmann, Adaptive Discontinuous Galerkin Methods with Shock-Capturing for the Compressible Navier-Strokes Equations, Int. J. Numer. Methods Fluids, 2006.

42. D.A. Schwer, R. Johnson, A. Kercher, D. Kessler, and A. Corrigan, "Progress in Efficient, High-Fidelity, Rotating Detonation Engine Simulations," AIAA Scitech 2019 Forum, 2019.
43. G. Karypis and V. Kumar, Parallel Multilevel K-Way Partitioning Scheme for Irregular Graphs, SIAM Rev., 1999.

44. N. Bell and J. Hoberock, Thrust: A Productivity-Oriented Library for CUDA, GPU Computing Gems Jade Edition, 2012.

45. C. Geuzaine and J.F. Remacle, Gmsh: A 3-D Finite Element Mesh Generator with Built-in Pre- and Post-Processing Facilities, Int. J. Numer. Methods Eng., 2009.

46. F.G. Keyes, A Summary of Viscosity and Heat-Conduction Data for $\mathrm{He}, \mathrm{A}, \mathrm{H}_{2}, \mathrm{O}_{2}, \mathrm{CO}, \mathrm{CO}_{2}, \mathrm{H}_{2} \mathrm{O}$, and Air, Trans. ASME, 1951, 73, p 589-596.

47. R.C. Dykhuizen, M.F. Smith, D.L. Gilmore, R.A. Neiser, X. Jiang, and S. Sampath, Impact of High Velocity Cold Spray Particles, J. Therm. Spray Technol., 1999, 8(4), p 559-564.

48. E.S. Hertel, R.L. Bell, M.G. Elrick, A. V. Farnsworth, G.I. Kerley, J.M. McGlaun, S. V. Petney, S.A. Silling, P.A. Taylor, and L. Yarrington, CTH: A Software Family for Multi-Dimensional Shock Physics Analysis, Shock Waves @ Marseille I, (Berlin, Heidelberg), Springer Berlin Heidelberg, 1995, p 377382.

49. H. Park, J. Kim, S.B. Lee, and C. Lee, Correlation of Fracture Mode Transition of Ceramic Particle with Critical Velocity for Successful Deposition in Vacuum Kinetic Spraying Process, $J$. Therm. Spray Technol., Springer US, 2017, 26(3), p 327-339.

Publisher's Note Springer Nature remains neutral with regard to jurisdictional claims in published maps and institutional affiliations. 